\title{
Vorstudien zu einer Psychologie der Manie.
}

\author{
Von \\ Paul Schilder (Wien). \\ (Eingegangen am 11. März 1921.)
}

\begin{abstract}
Wenn ein Mensch vor die Aufgabe gestellt ist, ein Denkproblem zu erledigen, so setzt eine Reihe seelischer Geschehnisse ein, welche nach diesem Ziel gerichtet ist, aber das Bestreben allein wird die lösung nicht erzwingen können, wenn nicht Vorbedingungen gegeben sind. $\mathrm{Zu}$ diesen gehören etwa: eine entsprechende Sachkenntnis, die Fähigkeit, Für und Wider überschauen zu können, das Freisein von trübenden Affekteinstellungen. Diese Vorbedingungen lassen sich in zwei Gruppen teilen, deren eine alles umfaßt, was geistiges Erbe und Konstitution ist, deren andere allen Nenerwerb des Individuums enthält und alle seine besonderen Erlebnisse. - Sehr ähnliche Erwägungen müßte man anstellen, um sich klarzumachen, warum der Wille zu einer bestimmten Innervation keineswegs diese zur Folge haben muß. warum der Wunsch, einen Gegenstand vorzustellen, diese Vorstellung nicht immer erweckt. - Es handelt sich also offenbar um ein wichtiges Prinzip in der Dynamik psychischen Geschehens. Diese Dynamik wird aber nicht nur von Vorsätzen und Entschlüssen beherrscht, sondern auch von Trieben, Einstellungen. Andernteils erscheinen im Verlaufe seelischer Geschehnisse ja nicht nur Gedanken, Innervationen und Vorstellungen, sondern auch Gefühle. Schließlich wird z. B. das Ausbleiben eines Denkresultates eine ganze Kette immer neuer Versuche hervorrufen können, einen Gefühlston der Mißstimmung über das Gesamterleben breiten, das Erreichen des Denkzieles kann hinwiederum ein Gefühl der Befreiung, der Heiterkeit erwecken und Anlaß geben zu einer erhöhten Tätigkeit. - Aber, wie schon betont, auch das Auftreten von Gefühlen und $\mathrm{MaB}$ und Intensität dieser Gefühle, sowie auch ihr Ausdruck sind von ,Konstitution“ und ,Disposition“ abhängig. Wenn etwa drei Darbende, deren äußere Verhältnisse man möglichst gleich denken möge, jeder die gleiche beträchtliche Summe Geldes erhalten würde, so wird das Gefühl des Glückes bei ihnen sehr verschieden sein. Es werden sowohl die psychischen Erlebnisse als auch die Entäußerung dieser Gefühle sehr verschieden sein. Aber nicht nur
\end{abstract}


das, auch die Nachwirkung dieses Erlebnisses wird sich auf verschiedene Zeitstrecken bemerkbar machen. Bei der sorgfältigsten individualpsychologischen Betrachtung wird sich immer nur ein Teil der Gesamtreaktion von Erlebnissen ableiten lassen, den anderen Teil wird man der ,Konstitution“ zur Last legen müssen.

Ähnliche Gedankengänge sind ja den Psychiatern geläufig. Die reaktiven Depressionen hat man ja mit ähnlichen Gedankengängen dem Verständnis nähergebracht. Reiss ${ }^{1}$ ) hat aber zwischen endogenen und reaktiven Depressionen alle möglichen Utbergänge finden können. Auch das Vorkommen ,reaktiver" Manien ist bekannt. Systematische Untersuchungen über die ,Dynamik“ der Affekte in dem oben angedeuteten Sinne stehen meines Wissens aber bisher aus.

Fall 1. Marie Z., 19 Jahre, in der psychiatr. Klinik der Univ. Wien vom l. II. 1920 bis 26 . V. 1920.

Nach den Angaben der Verwandten normal entwickelt, hat gut gelernt, war gutmütig, heiter, religiös. Zwei Geschwister. Eltern gesund. Am 28. Oktober 1918 kam sie nach Klosterneuburg in die Trrenanstalt, wo sie bis 15. III. 1919 verblieb. Sie war zu Hause in einem ständigen Bewegungsdrang gewesen, machte zwecklose Eisenbahnfahrten, verschwendete Geld. Lachte, sang viel, geriet aber auch leicht ins Weinen. Sah aber auch Menschen, welche zum Fenster hereinschießen wollten. Hatte Angstzustände. Nach der Krankengeschichte der Irrenanstalt: Gelegentlich zurückhaltend, meist aber schnippisch, gerät leicht in Erregung, gibt unpassende Antworten, ist heiter. Zeitweise gereizt. Zeigt eine Wunde am Arm, ein Major habe zum Fenster hereingeschossen. Spricht den Arzt mit „Du“ an, rechnet schlecht. Das Jahr habe 360 Tage. Die Donau münde in einen Bach in Ungarn. Ist von einer läppischen Heiterkeit. In der Folgezeit: Manieriert, großsprecherisch, theatralisch, meist heiter, kindisch, nur selten mißgestimmt, verdrossen, trotzig. Zu Hause beschäftigte sich die Pat. etwas im Haushalt. Vor der Einbringung wurde die Pat. wieder lebhaft und erregt.

In der Klinik erwies sich die Pat. als lebhaft und erregt, bei völliger örtlicher und zeitlicher Orientierung. Sie ist guter Laune, zu Scherzen geneigt. „Ich bin gegen alle grob, auch gegen einen Doktor, das macht mir nichts!“ „Ich bin immer lustig, auch wenn alle sterben, mach ich mir nichts draus!" Sie spüre Schmerzen in den Füßen, könne nicht schlafen. Lebhafte Aufmerksamkeit für die Umgebung. Abspringend. „Die Männer haß ich, einmal habe ich hoffnungslos geliebt." Die Periode sei in Ordnung, sie habe noch mit keinem Mann geschlechtlich verkehrt. Bewegungsreich. Sehr laut und lärmend. Scherzend: „Ich hab den Verfolgungswahn." Fortwährend lachend: „Ich bin so krank, ich bin zu stolz, um jemandem zu beichten. Ich freß alles selbst hinunter, das kommt in der Nacht." 1917-1918 sei sie in der Irrenanstalt Klosterneuburg gewesen. Dort fühlte sie sich verfolgt. Sie war von einem Major fur ein militärisches Bureau engagiert worden. Den Major liebte sie. Er lockte sie einmal in sein Zimmer und wollte ihr Gewalt antun. Der Revolver des Majors entlud sich bei der Balgerei, die entstand, der Schuß verletzte ihn an der Brust, die Pat. an den Knien. Dann sei sie ihm entflohen. In Klosterneuburg sah sie nur immer wieder den Major vor sich, der sie vergewaltigen wollte. Sie dachte auch, es sei ihm gelungen, sie zu vergewaltigen. Sie bildete sich ein, schwanger zu sein, und alle verachteten sie.

1) Konstitutionelle Verstimmung und manisch-depressives Irresein usw. Diese Zeitschr. 2. 347. 1910. 
Diese Angaben wiederholt die Pat. immer wieder. Während des ganzen Aufenthaltes in der Klinik war ihr Verhalten im Grund das gleiche; sehr erotisch und kokett, drängte sie sich an die Ärzte. In ihrer Zelle die größte Unordnung; sie putzt sich mit Bàndern und Tüchern, der ldeengang abspringend, ideenflüchtig. Heiterkeit, motorische Erregung, ist in fortwährender Bewegung. Witzelnd, häufig etwas manieriert. Zu Zornesausbrüchen, Losschlagen geneigt. Bei dem Versuche tieferen Eingehens auf Jugenderlebnisse u. dgl. Witze, Abspringen. Schreiblustig, träumt sehr viel. Über diese Träume gab sie gut Auskunft, schrieb sie auch nieder. Der Typus dieser Traume sei an drei Beispielen veranschaulicht:

Ich bin mit meinem Bruder auf der Wiese gelegen und habe die Ziegen auf der Weide gehalten, er hat auf der Flöte gespielt. Ich hatte eine Wut, sprang auf und sagte zu ihm: Wir wollen die Ziegen melken. Ich zog dann die Euter, und mein Bruder hielt den Hut unter, mein Bruder sagte, ich solle nicht so ziehen, damit es nicht so lang wird. Wir tranken dann die Milch aus dem Hut. Wir haben dann die Ziegen nach Hause getrieben, und die Mutter bemerkte, daß die Ziege wenig Milch hatte und der Euter weich sei. Ich sagte, daß wahrscheinlich das Zicklein getrunken hat, dann gestand ich, daß ich sie getrunken hatte.

Ich war auf einer Tanne oben und jagte nach einem Eichhörnchen, wir sprangen von einem Ast zum anderen und dann von einem Baum zum anderen, sie standen sehr dicht. Dann ließ ich mich zum Stamm hinunter. Ich riß mir am Oberschenkel die Haut auf, ich sah einen tiefen Riß und viel Blut. Unser Doktor sagte, das seien nur nervöse Bewegungen, und ich solle wieder nach Klosterneuburg. Mein Bruder gab Terpentin auf die Wunde. Ich sagte dem Doktor, ich werde ihn erschießen, bevor ich nach Klosterneuburg gehe, damit er wisse, daß ich verrückt bin. Mir kann nichts geschehen, ich komme höchstens in die Irrenanstalt.

(Bruchstück.) Auf einmal kam mein Kusin und holte mich zu einem Spazierritt ab; wir ritten dann durch einen Urwald und kamen in die entgegengesetzte Richtung über den Saubach, und der ist wirklich verhext. Nun so ritten wir und immer kamen wir an denselben Ort. Ich entschloß mich niederzulegen und zu schlafen, der Kusin ging entlang des Wassers und riß junge Bäumchen aus, um zu sehen, wo wir schon überall waren. Auf einmal schrie eine Hexe. Als ich sie sah, schrie ich auch und klammerte mich fest an Peperls Arm, daß dieser laut aufschrie. Dann bekam ich so eine Wut und haute mit dem Bäumchen fest drauf los.

Der Fall ist als Manie aufzufassen. Das gelegentlich beobachtete Grimassieren, die leichte Manieriertheit können an dieser Diagnose nichts ändern.

Die Erkrankung der Patientin wird eingeleitet durch ein aufwühlendes Erlebnis. Sie erleidet einen Vergewaltigungsversuch. Dieses Erlebnis ist objektiv nicht beglaubigt. Die Art, wie die Patientin darüber berichtet, macht es aber wahrscheinlich, daß es stattgefunden hat. Die Details sind aber sicherlich Ausschmückung. Es ist übrigens für die Schlußfolgerungen gleichgültig, ob es sich um Phantasie oder Wirklichkeit handelt. Daß ein entsprechender „Komplex“ zu Beginn der Erkrankung vorlag, ist durch die Angaben der Angehörigen und durch den Aufnahmebefund der Irrenanstalt bewiesen. Er bestand jedenfalls zu einer Zeit noch, als manische Symptome das Bild beherrschten. Der Komplex hat den Angaben nach eine hysteriforme Ausbildung erfahren. Die versuchte Vergewaltigung wird zu einer geglückten. 
Besteht eine Beziehung zwischen dem Komplex und der Manie? Kann ein aufregendes und unbefriedigendes Erlebnis wesentlich werden für die Entbindung von Heiterkeit, Bewegung und Ideenflucht?

In dieser Beobachtung steht nur wenig Material für die Beantwortung zur Verfügung. Ich habe zunächst versucht, in den Träumen Anhaltspunkte zu finden. Diese Träume zeigen aber folgendes: Sie sind bunt, bewegungsreich, vielfarbig, haben eine Fülle an Details. Die ruhelose Bewegung wird von der Träumerin selbst geleistet oder erscheint in der Außenwelt (Ritt). Die Tagesinteressen nehmen einen breiten Raum ein. Die Träume weisen eine sinnvolle Struktur auf. Erotisches bricht (in hier nicht wiedergegebenen Stücken) stark und unverhüllt hervor. Mit einem Wort: Der Unterschied zwischen dem Erleben des Traumes und des Wachens ist nicht groß. Auch im Traume gebärdet sich die Patientin als Manische. Nur daß im Traume auch die Szenerie „,manisch" ist. Diese Träume erinnern in vielen Punkten an Wachträumereien. Man glaubt, aus ihnen eine geringe Schlaftiefe ablesen zu können. Jedenfalls war ein tieferes Eindringen in die seelische Dynamik auf diesem Wege nicht möglich.

Es kann aber folgendes vermutet werden, unbefriedigende und erregende Erlebnisse müssen ja seelische Abwehrreaktionen in Gang setzen. Der Verlauf einer solchen Abwehr und Verarbeitung ist aber bestimmt durch Momente, welche außerhalb des unmittelbaren Erlebnisses liegen. Es könnte Tieferliegendes zum Durchbruch kommen. Bildlich: Es können Schleusen eröffnet werden, aus denen manisches Fluidum ausströmt.

Es ist zu beachten, daß der Komplex im Beginne der Manie noch besteht und den Hintergrund abgibt für die manischen Erscheinungen. Es ist deskriptiv scharf zu unterscheiden zwischen dem seelischen Selbstgenügen, dem fortwährenden wunschlosen Genießen, das wir bei einer Reihe Schizophrener sehen können, und jenem unruhigen, bewegten Zustand der allermeisten Manischen. Auch jene, welche nicht zu Zornausbrüchen neigen, sind durch kein erreichtes Ziel zur Ruhe zu bringen. Es eröffnet sich sofort ein neues Ziel, das in Unruhe und Hast erstrebt wird. Die motorische Unruhe kann als Beweis dafür gelten, daß es für den Manischen nichts Endgültiges gibt, daß ihm das Erreichte sofort entwertet ist. So daß es auch von diesem formalen Standpunkt aus als denkbar erscheinen muß, daß ungesättigte Komplexe tieferer Schichten bestehen geblieben sind.

Es bleibt also das Problem bestehen, ob nicht unerledigte Komplexe das Reservoir ,,manischen Fluidums" eröffnen können.

Uber dieses Reservoir zunächst einige Erwägungen: Eine schizophrene Patientin Paul. Skr. ${ }^{1}$ ) erleidet eine schwere katatone Phase

1) Der Fall wird andernorts ausführlich mitgeteilt. 
von funftägiger Dauer, sie ist verwirrt, unzugänglich, motorisch erregt. Der Inhalt dieses Erlebens konnte katamnestisch festgestellt werden. Ein ,,altes Gesicht", der Herrgott, eine deutliche Ersatzfigur für den innigstgeliebten, verstorbenen Vater, will mit ihr schlafen, die Mutter tritt hindernd dazwischen; sie wird vom Teufel geholt. Die Patientin ist das Höchste der Welt, weil sie kupplerische Pläne ihrer Mutter vereitelt hat. Es schließt sich an diesen Verwirrtheitszustand eine Phase ausgesprochener manischer Erregung an, die allmählich abklingt. Hier ist es also eine Wunscherfüllung (wenigstens eine teilweise), welche die manische Erregung bedingt und zur Folge hat. Wir wissen aber, daß nicht jedes ,Wunscherfüllungsdelir" derartig nachwirkt. Es muß also angenommen werden, daß noch andere ,biologische" Motive hier hineinspielen.

Eine Reindarstellung dieses biologischen Mechanismus gibt der folgende Fall:

Fall 2. Otto E., 17 Jahre alt. In der Klinik vom 4. bis 27. XII. 1920.

Nach den Angaben der Verwandten mit 5 Jahren Fraisen. I Jahr später epileptische Anfälle, meist ein-bis zweimal jährlich, später häufiger. In den Sommermonaten bleiben die Anfalle aus. 4 Tage vor der Aufnahme 4-5 Anfälle an 1 Tage. Seither war der Patient verwirrt. Anfälle mit Zungenbiß, Verletzung am Auge, ohne Secessus urinae. Nach den Anfällen, die als epileptische geschildert werden, Schlaf. Der Vater leidet an Bleivergiftung, er hat selten ahnliche Anfälle wie der Sohn.

Bei der Aufnahme und nachts ist der Pat. sehr unruhig. Somatisch: Rechtes Auge blutunterlaufen. Ecchymosen. Morgens logokloniert er: „Noch einmal.“ Starrer leerer Gesichteausdruck. Nennt auf Befragen Namen und Alter. (Wo sind Sie ?) „II. Bezirk. (Und jetzt ?) „Wo Sie ..." (Ratlos.) Behält kataleptiform die ratlose Geste der Hand bei. (Jahr?) ,1902 . . .“(Krank ?) „Ja, Nervenanfälle ... Vorgestern hab ich die ganze Nacht aufgeschrien, hab Schmerzen gehabt. Es ist aus mit mir ... Sie haben mir zu trinken gegeben ... Dann war ich in einem Bad." (Wer bin ich?) „Herr Doktor.“ (Spricht langsam und mühsam.) ,Zu Hause . . zu Hause . . zu Hause..." (Logokloniert.) (Bilder gesehen ?) „Was fur Bilder ... ıch bin ja ... bei ... bei ... das Ganze war nur deswegen, weil es sind zusammgestanden und da hat man wie eine Leiche ... dann hat er mich in eine Anstalt geführt. Da hat er so aufgeschmiert und eingestochen." Beginnt ih mühsam abgehackter Weise von den letzten Erlebnissen zu erzählen. Ist im allgemeinen interesselos für die Umgebung und ist nur wenig ansprechbar, fängt aber doch einzelne Brocken auf, die er logoklonierend wiederholt. Während der Untersuchung sagt er: „Es muß mir wer was gegeben haben, sonst könnt ich nicht so stinken." $(5 \times 7$ ?) Logokloniert $5 \ldots$ dann „Es tut mir zu weh . . ba . . ba ..." $(5 \times 7$ ? ) „Im Rechnen war ich immer ... war ... war ... ba . . ba ..." In den nächsten Tagen unverändert. Am 8. XII. äußert er, er werde jetzt beten. Der Herrgott habe ihm gesagt, er werde noch 53 Jahre leben. Am 10. XII. ist der Pat. klar und geordnet, ist lustig, gesprächig, läuft bei der Visite mit, redet drein. Sagt einem Arzt: „Sie gefallen mir, in sie bin ich verliebt." Über seine Eriebnisse gibt er gut Auskunft. Nach den Anfällen begann er zu schreien und schrie die ganze Nacht hindurch. Er hatte Angst, daß er sterben werde. Er glaubte, daß man ihn im Auto ermorden werde, dann da $B$ er mit Leichenpulver verschüttet werde. Er fühlte, wie er kalt wurde. Er wurde eine Leiche, die sehr stark gestunken hat, er ver- 
breitete eine Seuche rings herum und sah auch die anderen sterben. Den Hofrat hielt er für einen Polizeirat ... den Pat. hing das Fleisch herunter. Die Seuche hatte er dadurch in die Welt gebracht, daß er als Toter einen Tag lag. . . Die Leute sprangen aus dem Fenster. Auch der Vater war - so dachte er - von der Pest hinweggerafft. Dreimal starb der Pat. Bevor er starb, wollte er der Schwester einen Zettel mit einem Erkennungswort geben. Er wollte nämlich wieder, auferstanden, seine Schwester heiraten. Die Schwester sollte den Mann, den sie heiratet, als ihren Bruder dadurch erkennen, daß er ihr das auf dem Zettel geschriebene Losungswort sagt . . . Dann kam der Herrgott und sagte, er sei jung und ehrlich, er habe auch den Vater nicht verraten, der ihn mit Leichenpulver vergiften wollte; deshalb solle an seiner Stelle der Vater, der ohnedies 50 Jahre alt sei, sterben. Da spürte er, wie der Körper warm wurde und das frische Leben kam. In den folgenden Tagen hält die manische Erregung an, sie steigert sich sogar: Schreit und schimpft lebhaft über andere Patienten, witzelnd, bewegungsreich, guter Dinge, abspringender Gedankengang. Dabei faßt er gut auf. Beschreibt Bilder gut. Bis zum Tage der Entlassung (26. XII.) allmähliches Abklingen der Manie.

Es liegt keine Veranlassung vor, die Serie epileptischer Anfälle psychologisch zu deuten, ebenso muß die nachfolgende depressive Phase als unmittelbare Darstellung der physischen Vernichtung aufgefaßt werden, das allmählich anschwellende und wieder abschwellende manische Stadium kann wiederum nur als Reflex der biologischen Restitution angesehen werden. Es ist beachtenswert, daß Komplexe (Heirat mit der Schwester, Tod des Vaters) in die Höhe gerissen werden und am Úbergang der depressiven in die manische Phase auftauchen. Sicherlich ist aber der Komplex nicht Ursache der depressiven Phase und seine Iösung nicht Ursache der manischen Phase. Die „Manie“ ist hier ein somatisch-biologischer Vorgang im ,Reservoir".

Die bisherigen Erwägungen führen zu folgenden Gesichtspunkten: Es gibt somatogene, biologische Schwankungen im „Reservoir". Aber das Reservoir kann angerufen werden sowohl dadurch, daß ein Komplex eine teilweise oder vollständige Lösung erfährt, als auch dadurch, daß ein Komplex eine Lösung nur fordert.

Ein solcher ungelöster Komplex liegt in der nun folgenden Beobachtung vor:

Fall 3. Marie M., 24 Jahre alt, in der psychiatrischen Klinik vom 13. XI. 1920 bis Februar 1921.

Die Pat. hatte am 11. XI. Veronal in selbstmörderischer Absicht genommen. Am Abend des 12. XI. nach vorausgegangener Benommenheit große Unruhe. Schreit, lacht, singt. Will im Hemd ins Stiegenhaus. Spricht mit ihrem kürzlich verstorbenen Vater. Ist desorientiert, am nächsten Tag aus dem Peripheriespital in die Klinik.

Antwortet abschweifend, ist räumlich und zeitlich nicht orientiert. Zeigt eine leicht manische Erregung. Sie gibt an, sie sei 4 Monate im Wilhelminen-Spital gelegen, erst mit Perikarditis, dann mit Gonorrhöe $\left.{ }^{1}\right)$. Sie sei hergefahren, weil

1) Nach der von dort eingeholten Krankengeschichte vom 12. VII. 1920 bis 10. XI. 1920 wegen Arthritis gonorrhoica, Polyarthritis und Endometritis behandelt. Beginn zirka 4 Wochen vor der Aufnahme. Geheilt entlassen. 
man ihr sagte, der Vàter sei hier. Sie spricht immer von diesem. „Der Vatel. ist im Grübl am Ottakringer Friedhof." Er hat gesagt: „Hast auch Platz!" Sie sagt: „Bin schon gestorben.“ Auf einen Einwand: „Sie sind wahrscheinlich der Herrgott." Auf die meisten Fragen: „Ich bin beim Vater im Grübl." Ferner: „Ich hab im Leben nicht anderes gegessen als Gift.“ Dann zeitweise ganz ge. ordnet. Benimmt sich so, als sehe sie den Vater neben sich im Bett. Der Vater sei im Mai dieses Jahres gestorben. Einfachste Fragen $(2+2$ ?): , . . Ich weiß momentan nicht." $(2 \times 5$ ?) ,Ich muß erst Vater fragen ..." (Wie viele Beine hat das Pferd?) "Morgen sag ich es bestimmt, bis ich es mit dem Vater besprochen hab." Einen vorgehaltenen Bleistift bezeichnet sie als Schokolade. Vor einem Jahr sei sie mit einem Liebhaber gegangen, dieser Schuft habe sie verlassen, als sie wegen der Gonorrhöe, die sie von ihm hatte, ins Spital kam.

Auch in den nächsten Tagen, es gehe ihr ausgezeichnet, sie sei tot, der Vater habe sie geholt, sie sei mit ihm zusammen im Grübl. Manisch. Gelegentlich: Hält den Arzt für einen Pfarrer. Dann wieder, ob er zum Heurigen gehe. Verlangt einen Tschik. Will den Franzl (ihren Liebhaber) umbringen, ihm die Gurgel abschneiden. Am 20. XI. erklärt die Pat., in der Nacht komme der Vater zu ihr und zupfe sie. Dabei stets lustig, bewegt, bummelwitzig bei abspringender Aufmerksamkeit. Die Orientierung ist jetzt eine vollkommene.

Somatisch ist als Folge der Veronalvergiftung Nystagmus rotatorius nach rechts und links nachweisbar und Vorbeizeigen in beiden Armen nach außen. Schwindel. Fallen nach hinten ${ }^{\mathbf{1}}$ ). - Die Schmerzempfindung und der Rachen. reflex sind etwas herabgesetzt. Keine Druckpunkte.

In der Folgezeit hält die manische Stimmung an. Doch ist die Pat. über alles das orientiert, was'zum Selbstmordversuch Anlaß gegeben hat. Sie sei unglücklich gewesen über den Tod ihres Vaters (Mai 1920), ihre 65 jährige Mutter habe nach kurzer Zeit wieder geheiratet. Ihr Geliebter habe sie angesteckt, habe sie dann verlassen und lebe jetzt mit einer anderen. Den Selbstmordversuch machte sif am Grabe des Vaters einen Tag nach ihrer Entlassung aus dem Spital. Bei diesen Berichten kommt ein sehr starker depressiver Affekt zustande, der aber sofort wieder in ausgelassene Heiterkeit umschlägt.

Die Liebe zum Vater ist überhaupt der beherrschende Zug ihres Seelenlebens. Hierfür ließ sich ein experimenteller Beweis erbringen. Die Pat. erwies sich als leicht hypnotisabel. In der Hypnose erhielt sie den Befehl, etwas Angenehmes zu sehen; daraufhin sah sie ihren Vater vor sich, streckte sehnsuchtsvoll die Arme nach ihm aus und rief: „Mein Vaterl, mein Vaterl.“ Erweckt, war sie völlig amnestisch für das in der Hypnose Erlebte. Sie war stark deprimiert, ohne eine Ursache anzugeben. Diese Depression schlug plötzlich in eine erhöhte Heiterkeit um, sie klatschte in die Hände und machte fröhliche Bemerkungen. Dieser Versuch wurde nach einigen Tagen mit dem gleichen Erfolg wiederholt. Die Pat. gab an, vor dem Eintritt des hypnotischen Schlafes ein besonders angenehmes Gefühl der Wärme im ganzen Körper gehabt zu haben. Nach dem Erwachen klagte sie über Kopfschmerzen. Über den Vater berichtet sie, sie habe ihn immer besonders gern gehabt. Sie war auch sein Liebling. Als sie mit 16 Jahren an einen älteren Mann verkauft. wurde, hielt sie bei ihm nur deshalb aus, weil es ihr Freude machte, den Vater zu beschenken und zu unterstützen. Als Schulkind schwänzte sie die Schule, um mit dem Vater - der Kutscher war - zu fahren. Sehr charakteristisch ist ein Traum. Sie sah einen großen, sehr mageren Mann, der wie ein Skelett dalag, er war umgeben von kleinen Kindern, die alle tot in Truhen lagen. Sie glaubte, der Mann sei auch tot. Plötzlich erhob er sich und schaute sie an. Sie erschrak und ging aus dem

1) Fremel und Herrschmann werden uber diese Dinge ausführlicher berichten. 
Zimmer. - In diesem Traum meint sie, der Vater habe sich angezeigt und erzählt, wie sie bei dem Tode des Vaters das aus dem Sarge rinnende Leichenwasser aufgewischt hätte. Mit ihren 5 Geschwistern (die alle geistesgesund sind) steht sie jetzt gut. Der Traum ist wohl als Ausdruck kindlicher Eifersucht gegen die Geschwister aufzufassen. In den letzten Tagen des Dezember wird sie oft traurig und weinend angetroffen, sie denke an den Vater. "Niemand hat den Vater so gern wie ich."

Gegen die Mutter äußert sie unverhüllte Abneigung und Haß. Oft droht die Pat., sie wolle sie umbringen, weil sie wieder geheiratet hätte. Sie hat das im Traum auch ausgefübrt.

In der Klinik faßt sie Zuncigung zu einem Arzt. Wiederholt äußert sie, sie möchte dessen Frau am liebsten umbringen.

Ihre erste Depression hatte die Pat. mit 16 Jahren. Sie war damals verliebt in einen älteren, etwa 40 jährigen, verheirateten Mann, wagte aber diese Liebe nicht zu äußern. Die Frau hat sie in Gedanken ermordet. Sie machte damals auch einen Selbstmordversuch. Nach einigen Monaten wurde sie wieder lustig. Die genaue zeitliche Datierung dieser und anderer depressiver und manischer Phasen ist nicht zu eruieren. Jedenfalls hat die Pat. ein bewegtes Leben geführt, war Pflegerin, hat eine Gefängnisstrafe von 3 Monaten wegen Hochstapelei - sie trat als Baronin auf - verbüßt. Über eine Reihe von Details verweigert die Pat. Auskünfte. Die Wut gegen ihren früheren Geliebten ist andauernd, sie träumt, er wolle sie erschießen, oder sie mache ihm Vorwürfe u. dgl. Zu einem tieferen Eingehen z. B. auf die Kindheitsgeschichte ist sie nicht zu bringen.

Die auf der Veronalvergiftung beruhenden Symptome sind gegen Ende der Beobachtung nur in sehr geringem Grade mehr nachweisbar.

Sicherlich handelt es sich um eine zirkuläre Psychose. Die jetzige Phase der Psychose schließt an einen Selbstmordversuch durch Veronal an. Der Selbstmordversuch ist hinlänglich in der Untreue des Geliebten, in der Erkrankung an Gonorrhöə, in dem Tod des Vaters und der Wiederverehelichung der Mutter motiviert. Die halluzinatorische Psychose unmittelbar nach dem Selbstmordversuch stellt das Erlebnis mit dem Vater in den Vordergrund. Am Grabe des Vaters hat sie auch den Selbstmordversuch unternommen. Auch in der Manie ist dieser Komplex ständig nachweisbar. Besonders deutlich zeigt das der Hypnoseversuch. Sie halluziniert spontan den Vater, als sie den Befehl bekommt, etwas Angenehmes zu sehen. Depressiver Affekt nach der Hypnose (trotz der Amnesie), dann erhöhte Heiterkeit. Man kann annehmen, daß die Depression in ursächlichem Zusammenhang mit der Manie steht. Es ist nicht auszuschließen, daß die Zwischenschaltung des Veronals für die Eröffnung des „Reservoirs“ mitbestimmend war. Das berührt das Grundproblem nicht. Es ist bemerkenswert, wie der Kummer der Patientin durch die Manie nur übertönt wird. Es ist diese Manie nicht die erste Erkrankung. Die erste Erkrankung schließt an an einen Liebeskummer. Man darf vermuten, daß der Ödipuskomplex auch in diese erste Depression mit nachfolgender Manie mit hineingespielt hat.

Auch in der folgenden Beobachtung ist der Tod des Vaters das auslösende Moment für die Depression, der die Manie folgt. 
Fall 4. Elisabeth A., 21 Jahre alt, in die psych. Klinik aufgenommen am 26. X. 1920.

Die objektiven Angaben stammen von der Mutter und vom Onkel (der Psychiater ist). Vater starb 1917 an progressiver Paralyse. Eine Schwester des Vaters hatte eine kurzdauernde Melancholie. Eine Kusine des Vaters seit mehreren Jahren in einer Irrenanstalt wegen Verfolgungswahn. Ein Vetter des Vaters starb durch Suicid. Die Pat. ist das zweite Kind von drei Geschwistern, von denen das älteste im Alter von zwei Jahren an Diphtherie starb. Die Pat. zeigte keine Erscheinungen hereditärer Lues. Sie lernte frühzeitig sprechen und laufen. Von Kinderkrankheiten Keuchhusten und Masern. In der Schule lernte sie gut, faßte rasch auf, verga $\beta$ aber auch rasch. Mit 11 Jahren erste Menses. 1914 trat Müdigkeit und Gefühl der geistigen Unzulänglichkeit zeitweise hervor. 1917 starb nach längerer Erkrankung der Vater. Die Mutter wurde an der Brust operiert. Die Pat. kränkte sich sehr. Mai bis September 1918 Melancholie. Von da ab Herbst und Winter expansiv, Frühjahr und Sommer depressiv. Gegen die Mutter ist sie grob, eigensinnig und sprunghaft. Während der melancholischen Phasen appetitlos.

In der Klinik zeigt die Pat. eine ausgesprochene manische Vielgeschäftigkeit, sie schreibt sehr viel, spricht viel. Sie ist abspringend im Gedankengang, ist bewegungsreich. Doch wird die äußere Ordnung des Gedankenganges nie gestört. Sie sucht Gesellschaft, will immer von den Ärzten unterhalten sein. Die Grundstimmung ist ausgesprochen heiter, doch schieben sich sehr viele depressive Elemente ein. Sie ist leicht zum Zürnen und Weinen zu bringen. Die äußeren gesellschaftlichen Formen werden innegehalten. Ihr Selbstbewußtsein ist im allgemeinen gesteigert; der unmittelbare Anlaß zur Einlieferung in die Klinik war gewesen, daß sie eine Nacht bei einem jungen Mann verbrachte. Sie war damals menstruiert. $\mathrm{Zu}$ einem Geschlechtsverkehr ist es nicht gekommen. Sie erzählt unumwunden von einer Fülle kleiner Abenteuer mit Männern, die alle recht harmlos verlaufen sind. Auch in der Klinik ist sie sehr erotisch, beteuert immer wieder ihre Liebe zu einem verheirateten Arzt, dem sie sich auf alle Weise zu nähern versucht.

Die Analyse deckte auf eine ungemeine Anhänglichkeit und Zärtlichkeit für den Vater. „... Mit 5 Jahren trug ich eine Puppe, die ich zerbrochen hatte, zum Doktor, als ich 6 Jahre alt war, wünschte ich mir, der alte Hausarzt möge mich küssen ... Ich war schon als Kind sinnlich erregt, wenn ich geküßt wurde, sogar, wenn mein armer Papa mich küßte... mit 16 Jahren nahm er mich noch auf den Schoß und hätschelte mich ... Ich dachte, ein Vater kann zu seinem Kind gar nicht so zärtlich sein ..." Mit 12 Jahren dachte sie, sie würde den Vater heiraten, ,er war ihr im Charakter so ähnlich, sie dachte, wenn sie mit ihm verheiratet sein werde, würde sie ihn glücklicher machen als die Mutter. Sie ließ sich von der Mutter gerne über die Werbung des Vaters, über die Verlobung usw. erzählen. Schon als Kind hing sie besonders am Vater. Sie konnte nicht einschlafen, wenn er verreiste. Sie mußte immer denken, er ginge in den Wald und dort erschieße man ihn. Im Jahre 1913 verlor der Vater sein Vermögen, es gab viel Zwist im Haus. 1915 erkrankte der Vater, die Erkrankung stimmte die Pat. sehr traurig. Sie besuchte ihn oft in der Irrenanstalt. 1917 starb er, die Pat. war nun sehr traurig. Sie hatte auch Zwangsvorstellungen, sie sei schuld, daß 3 der Papa krank geworden sei, weil sie ihn durch Lachen geärgert hatte. Auch die Mutter hat ihr einmal etwas Ähnliches gesagt. In der Melancholie, die nun folgte, wollte die Pat. nicht essen und sprechen. Sie kam sich minderwertig vor, wollte sich nicht anziehen.

Mit der Mutter hat sich die Pat. nie vertragen, sie hat sie nie gern gehabt. Sie hat während der vorangehenden Manien sehr häufig von der Mutter geträumt, daß diese sie beschimpfe und sekkiere. Auch während der jetzigen Beobachtung kehren immer solche Träume wieder: „Träumte sehr unangenehm, daß mich 
meine Mama und meine Schwester entsetzlich sekkierten. Wachte auf, schlief wieder ein und träumte dasselbe weiter. Ich weinte die ganze Nacht." Derartige Träume kamen immer wieder. Tagsüber äußert die Pat. immer wieder Besorgnisse, was denn sei, wenn sie entlassen würde, ob die Mutter sie nicht allzu sehr quälen würde. Sie hat oft gedacht, sie müsse die Mutter erschlagen. Sie sei als Kind schon zornig gewesen, habe ihre Puppe hingehauen, habe allerdings geweint, wenn sie zerbrach. Erotische Komplexe drängten sich immer wieder vor. Sie erzählt von den Abenteuern, Verlobungen. In den Träumen kommen diese Motive wiederholt zum Ausdruck. Sie träumt von Hochzeitsreisen. Diese Träume sind wiederum sehr reich an Details. Ein Teil eines derartigen Traumes sei wiedergegeben: Sie träumte von ihrem Bräutigam, der dem Ref. aber merkwürdig ähnlich sah, er war krank und lag im Bette. Er hatte Grippe. Sie machte ihm Umschläge. Sie waren allein, er war sehr zärtlich, er versprach, daß er sie trotz der Krankheit heiraten würde. (Im weiteren Verlauf des Traumes Verlobungsfeier und Hochzeitsreise.) Zu diesem Traum ist zu bemerken, daß damals der Arzt, den sie zu lieben angab, an Grippe erkrankt war, so daß die Liebesfigur des Traumes aus Verschmelzung dreier Figuren entstanden ist. Die Pat. klagt über sexuelle Unbefriedigung, sie betont immer wieder, sie werde nach der Entlassung ein Verhältnis beginnen. In einem ihrer Träume erscheint dieses Motiv in der Form, daß ihr ein Mädchen, das auf einer Redoute fortwährend die Kleider wechselt, Anspielungen macht, die Pat. habe nur ein Kleid. In einigen Skizzen, die sie schreibt, spielt das Thema der Prostitution und des lockeren Lebenswandels eine sehr große Rolle. In einem Traum wird das Zusammensein mit dem Bräutigam durch das Schimpfen der Mutter gestört.

Díe Pat. neigt zu lauten Klagen und Weinausbrüchen. Sie jammert dann, sie sei im Sommer melancholisch und könne im Winter ihr Leben auch nicht genießen. Sie äußert Angst vor der Melancholie. Wiederholt träumt sie, sie sei melancholisch, liege regungslos im Bett und wolle nicht aufstehn. Bei der Erzählung solcher 'Träume kommen wohl auch Äußerungen wie ,ihr Leben sei verpatzt". Sie berichtet, schon als Kind habe sie in Gesellschaft oft nicht reden können. Sie habe sich oft Vorwürfe gemacht, daß sie gegen ihren Vater zu wenig zärtlich sei. Die Geschichte der frühen Kindheit ergibt - soweit sie aufgeklärt ist - nichts Wesentliches. Im allgemeinen ist das Bild heiterer Vielgeschäftigkeit mit Reizbarkeit und abspringendem Ideengange vorherrschend.

In dieser leichten Manie kommen immer wieder Haßeinstellungen gegen die Mutter zum Durchbruch. Sie zeigen sich besonders in den Träumen. Die Liebe zum Vater kann als weiteres wesentliches Merkmal des inhaltlichen Erlebens bei dieser Patientin angesehen werden. Auch hier treten also ,,unerledigte Komplexe“" immer wieder hervor und erzwingen die Aufmerksamkeit der Patientin.

Fall 5. In dem nächsten Falle (Berta F., 24jähr.), die ich nur kürzere Zeit beobachtete (vom 1. IX. bis 12. IX. 1920), handelt es sich um eine Hypomanie; die bewegliche, meist heitere Pat, ist ideenflüchtig, bewegungsreich. Sie hat vor der Einlieferung eine Reihe erotischer Beziehungen angeknüpft, die jedoch harmlos verblieben. Zeitweise bejammert sie ihr Schicksal. Sie ist etwas zanksüchtig. Auf die Mutter ist sie nicht gut zu sprechen. „Die schönste Zeit meines Lebens war, als ich mit meinem Vater 6-8 Wochen in T. war. ... Wenn ich Arm in Arm mit ihm ging, hielt man uns für Geschwister oder für ein Brautpaar. " Mit 19 Jahren traten Migräneanfälle auf. Mit 22 Jahren eine Depression, welche nach mehrmonatiger Dauer mit einer leichten Hypomanie endigte. Danach Gesundung. 
Von Dezember 1919 bis Juli 1920 neuerliche Depression. Nach kurzer Pause Hypomanie, in der sich die Pat. zur Zeit der Aufnahme befand. Während der Depressionen träumte sie fortwährend vom Vater. Er sagte nie etwas, sah sie nur vor. wurfsvoll und mitleidig an. Die Träume waren konfus ... Sie freute sich immer, wenn sie ihren Vater sah ... In der Früh war sie enttäuscht, daß es nur ein Traum war ... Auch von einem jungen Mann träumte sie. Während der Hypomanie ist der Trauminhalt nicht sehr verändert. Einmal träumt sie von ihren Freunden, dann in einem komplizierten begebnisreichen Traum von ihrem Vater. In den Tageseinfällen kommen immer wieder erotische Wünsche, Sehnsucht nach Kindern und kleine Konflikte mit den Brüdern. -

So unvollständig diese Beobachtung ist, sie zeigt doch wieder die starke Bindung an den Vater, welche sowohl in der manischen, als auch in der depressiven Phase immer wieder durchbricht.

Diese drei Beobachtungen sind einander außerordentlich ähnlich. In allen ist es das Verhältnis zum Vater, das das Bild beherrscht. Uther diesem Komplex ist die Manie aufgebaut. Man kann in allen Fällen eine ursächliche Beziehung zur Manie nicht von der Hand weisen. Es läßt sich ohne weiteres zeigen, daß dieser Komplex während der ganzen Dauer der Beobachtung als wirkend nachweisbar ist und man kann insbesondere auch nach dem Ausfall des Hypnoseversuches vermuten, daß er als dauernder Anreiz anzusehen ist, durch eine erhöhte Úberwindung zur Lust zu gelangen. Hier liegt offenbar eine besondere Art vor, wie das Individuum mit einem Komplex fertig wird. Eine Uberschüttung, ein Ubergießen des Komplexes, der aber als solcher innerlich unbearbeitet bleibt.

Die negativen Einstellungen zur Mutter sind allen Fällen eigentümlich. Es läge demnach unverhüllt der Ödipuskomplex vor. Im Falle 4 konnte das Grobsexuelle sichtbar gemacht werden. Da gerade an diesem "Komplex" sich eine Reihe von Kontroversen und Mißverständnissen knüpft, so seien einige Worte hinzugefügt. Unter dem Ödipuskomplex ist hier zu verstehen sinnliche Liebe zum Vater und Todeswünsche gegen die Mutter. Der Ödipuskomplex geht zurück auf Kindheitserlebnisse. Das heißt aber sofort folgendes: Der Begriff Vater hat ganz andere Grenzen, als er bei dem Erwachsenen hat. Er vertritt alles, was mächtig ist, was Autorität ist, was Liebe erweckt. Man kann vermuten, daß auf dieser Stufe des Denkens jeder Einzelbegriff vertreten kann alle anderen der gleichen Sphäre angehörigen Begriffe. In diesem Einzelbegriff klingt die Sphäre viel hörbarer mit. Individualbegriff und Allgemeinbegriff zeigen merkwürdige Úbergänge ineinander. Man hat anzunehmen, daß nicht nur die Begriffe, sondern auch die Gefühle und Strebungen derartige „Verschmelzungen“ eingehen, so daß sinnliche und geistige Liebe ungetrennt sind und daß in dem Sinnlichen das Geistige und umgekehrt viel ausgeprägter mitschwingt als bei differenzierten Formen des Erlebens. Es gibt nun sicherlich 
auch beim Erwachsenen derartige archaischen Schichten, in denen Differenzierungen aufgehoben sind, Individualbegriffe der gleichen Sphäre miteinander vertauscht werden, ein Allgemeinbegriff durch einen Individualbegriff ersetzt wird u. dgl. m. Diese archaischen Schichten kann man als das Unbewußte bezeichnen. Hier gilt der Ödipuskomplex. Man muß also diesen Begriff aus der Sprache des „Bewußten“ in die des Unbewußten übersetzen, wenn man ihn richtig verstehen will. Versteht man ihn im groben Wortsinn, so wird man ihn häufig vergeblich suchen $\mathbf{1}$ ).

In der nachfolgenden Beobachtung tritt ein bestimmtes trauriges Erlebnis im Verlaufe der Manie immer wieder hervor.

Fall 6. Therese M., geboren 1866.

Erste Erkrankung der Pat.: Vom 7. XI. 1890 bis 17. IV. 1891 in der niederösterreichischen Landesirrenanstalt. Der Vater gibt an: Großeltern an internem Leiden gestorben. Vater gesund. Mutter reizbar. Eine Schwester des Vaters war vor mehreren Jahren geisteskrank, soll gegenwärtig gesund sein. Sonst in der Familie keine Nerven- oder Geisteskrankheiten. Sechs Geschwister der Pat. normal. Eines an Lebenschwäche gestorben. Als Kind war die Pat. immer gesund, hat nie an Fraisen gelitten. Gut und leicht gelernt, von reizbarer Gemütsart. Schulbesuch bis zum 14. Lebensjahr. Eintritt der Periode mit dem 13. Lebensjahr. September 1890 kränkte sich die Pat. sehr, daß sie lange keinen Dienstplatz fand, weinte viel und war traurig. Seit 8. IX. unmotivierter Stimmungswechsel, lachte in einem fort, tanzte viel, schrie ,heut fahr ich im Fiaker zum Kirchtag. " Machte Spektakel, lief vom Hause weg. Neigung zu Zornausbrüchen, in denen sie alles zerschlug und zertrümmerte. Seit Anfang September schlaflos. Seit dieser Zeit ist die Menstruation ausgeblieben.

Somatisch zeigt die Pat. nichts Auffallendes. Bei der Aufnahme unruhig, heiter, sehr gesprächig, verspottet die Umgebung, nimmt anderen Kranken Kleider, Schuhe weg, verlangt Mieder und Bänder, um sich damit zu schmücken, läuft auf der Abteilung umher, rauft bei der Sperrtüre, muß während der Besuchszeit ins Gitterbett gebracht werden. Die sprachlichen Äußerungen der Kranken sind verworren, unzusammenhängend. Bei Fragen vergißt sie die Frage und springt auf Fernerliegendes ab. Dabei Krankheitsgefühl, „der Schädel ganz verdreht", sie könne nichts mehr ordentlich denken. Ehe sie ein Wort ausgesprochen habe, komme ihr schon ein zweites in den Mund. Auch auf der Abteilung ist die Pat. in großer Unruhe, heiter gestimmt, lustig, gesprächig, ist ideenflüchtig, zeigt Bewegungsdrang. Über Ort und Zeit ist sie nur mangelhaft orientiert. Keine Halluzinationen, keine Wahnideen, zu Zeiten stärkerer Frregung verkennt sie die Umgebung. Am 9. XI. zornige Erregung, weil ihr ein Chloralpulver aufgenötigt worden war, weint, schimpft über die grobe Behandlung. 10. XI. Wieder heiter, aufgeräumt wie vorher, springt umher, lacht, pfeift, singt, kennt den zu Besuch anwesenden Gatten einer Pat. Im nächsten Monat tritt Reizbarkeit und Zornmütigkeit hervor. Verlangt nach Hause. Wolle ordentliche Kleider, lasse sich nicht herumstoßen und beschimpfen. Sie halluziniert seit einiger Zeit, horcht beim Fenster, droht mit den

1) Vgl. auch meine Bemerkungen in Wahn und Erkenntnis, Springer 1918. Daß man den Ödipuskomplex in dem oben angedeuteten Sinn verstehen könnte, war mir damals noch nicht klar. Vgl. über diese Dinge auch meine Arbeit über Gedankenentwicklung dieser Zeitschr. 59. Die psychoanalytischen Darstellungen legen allerdings das oben hervorgehobene Mißverständnis vielfach nahe. 
Fäusten hinunter, sie habe niemanden einen Schlampen abgegeben. Sie lasse sich das nicht gefallen. Schläft wenig. Über den Verstimmungszustand verweigert sie die Auskunft. „Sind sie der Beichtvater, daß sie alles zu wissen brauchen ?“ In den nächsten beiden Monaten ist die Pat. im allgemeinen ruhiger; aber noch immer reizbar und zornig, ist aber sonst in sich gekehrt, verkehrt nicht mit ihrer Umgebung. Im Gespräch ist sie meist abweisend, weil man sie hier zuruckhalte. Sie ist dabei deutlich ideenflüchtig, ist nur schwer bei der Sache zu erhalten, schweift fortwährend vom Thema ab. Wenig ausgeprägt ist der Bewegungsdrang. Zeitweise ist die Pat. eher gehemmt, sitzt mit zu Boden gerichtetem Blicke längere Zeit auf einem Fleck. Die Stimmung ist vorwiegend traurig. Am 12. III. ist sic weniger gehemmt, beschäftigt sich fleißig, schläft gut. Zeitweise traurig, verstimmt. Am 4. IV. 1891 erweist sich die Pat. als normal. Sie gibt auch jetzt gut Auskunfte: Schon vorher krank, habe sie sich im August 1890 überanstrengt, die Menses seien sehr stark gewesen. Sie fühlte sich matt und war zu keiner Arbeit aufgelegt. Häufig heftiger Kopfschmerz. Anfangs September erschrak sie über einen Betrunkenen, den sie im Wartesaal stehen sah. Am nächsten Tag regte sie sich über Krankheit einer Freundin auf. Sie nahm Medizin, glaubte dann, sie sei vergiftet. Dann verwirrt. Sie habe schreckliche Angst ausgestanden, Lärm und Pferdegetrampel gehört, glaubte, sie werde erschossen. Die Umgebung kam ihr verändert vor. Bald schien alles freudig, heiter und geputzt wie zur Hochzeit, bald wieder war ein wildes Durcheinander, Lärm, Zerstörung und Verwirrung. Sie weiß sich dunkel zu erinnern, daß sie August und September 1890 zu Bette lag, Umschläge und Medizin bekam u. dgl. Von ihrem Vater habe sie erfahren, daß sie viel geschrien und für alle gebetet habe, weil sie gedacht habe, es würde alles zugrunde gehen. Im Oktober 1890 habe sich dann alles geändert. Sie fühlte sich stark, gesund und kräftig wie nie, trotzdem sie schlecht aussah. Sie war heiter gestimmt, aufgeräumt, wollte sofort in den Dienst gehen und geriet nur darüber in Zorn, daß man sie nicht fortlassen wollte. Sie erinnert sich daran, daß sie gesprächig war, gleich bereit, grob oder schnippisch zu antworten. Sie war ideenflüchtig, hatte Bewegungsdrang. Erst nach längerer Zeit erfuhr sie, daß sie in der Irrenanstalt sei. Zu Beginn ihres Aufenthaltes hörte sie vom Fenster hinaufrufen "Schlampen, Hure", sie ärgerte sich darüber sehr. Die Pat. wurde völlig geheilt entlassen. Die Diagnose lautete: Manie.

Die Pat. hat mit 39 Jahren geheiratet. Oktober 1918 starb ihr Mann. Die Ehe blieb kinderlos. Die Pat. wurde am 10. August 1919 neuerdings in die Klinik eingeliefert. In den 29 Jahren der Zwischenzeit war sie psychisch nicht auffällig ge. wesen. 14 Tage vor der Aufnahme wurde die Pat. unruhig, sah ihren Mann, war aggressiv, wollte sich vor einen Zug werfen. Beim Examen in der Klinik dreht sich die Pat. fortwährend um, sie wolle fort. Sie wisse nicht, warum sie da sei. Dann ,ach ja, ich weiß schon warum“. Plötzlich weinerlich: „Ach warum mußich denn so unglücklich sein ?" Beachtet lebhaft die Umgebung. Auf eine Bemerkung eines Arztes, es sei wenig Platz hier, ,lassen sie mich nach Hause, dann wird Platz sein ..." Verläßt ungeduldig ihren Platz, setzt sich auf einen anderen Sessel. Auf die Frage, weshalb sie sich das Leben nehmen wollte, gleichgültig: „Weiß ich ?6* Klopft mit dem Fuß auf den Fußboden, dann mit der Faust auf den Tisch, ,zu dumm, daß ich da so lange sein muß." „Jetzt sind die Ärzte nicht mehr so grob wie früher." Dabei wird sie fröhlicher, spricht jetzt spontan andere Ärzte an, spielt mit auf dem Tische liegenden Sachen ... Will nichts näheres mitteilen, ,,alles braucht man nicht zu sagen." Sie war schon einmal in der Klinik, das Jahr will sie nicht angeben. Schnippisches Wesen, der heitere Affekt bricht immer wieder durch. Gegen die körperliche Untersuchung sträubt sie sich, kneift die Augen zu. „Verbrennen sie meine Haare!" schreit sie beim Beklopfen der Patellarsehnen. 
Am 12. VIII. schalkhafte Ablehnung, lacht, bietet dem Arzt Brot an. „Na, Sie mögen halt keins, haben sicher was Besseres als ein Brot." Auf eine Orientierungsfrage: „Ja, das müssen Sie so sehen, wo ich bin.“ Zum Arzt: „Na, Sie, mein Mam ist mir schon lieber als Sie." Nur wenig ablenkbar, schenkt der Umgebung nur wenig Beachtung. 13. VIII. Bei der Frage nach dem Mann wird die früher heitere Pat. plötzlich ganz traurig, meint, wenn Doz. P. dagewesen wäre, wäre ihr Mann nicht in die Irrenanstalt gekommen $\left.!^{1}\right)$ Fragt einen Arzt, ob er der Dozent P. sei... (Wo sind sie?) „Sie wissen doch im Irrenhaus!" Sei zum erstenmal hier, wird wieder ablehnend. (Weshalb sind Sie da?) „Das brauchen Sie nicht zu wissen!" Drängt nach Hause. Am 14. VII. berichtet sie wieder von der Behandlung ihres Mannes durch Dozent P. ..., und daß ihr Mann wie ihre Mutter gestorben seien. An diesem und den folgenden Tagen ist das Gesamtbild nur wenig verän. dert. Sie ist nun bedeutend zugänglicher. Heiteres, schnippisches Wesen. Dazwischen immer wieder Momente einer echten Depression, sie wird traurig, weint, doch versiegt das Weinen rasch. Verlangt nach Hause. Am 17. VIII. ist sie sehr lärmend, schreit und singt. Berichtet, der Mann sei gestorben, es sei nur ein Traum, daß er gelebt hat. Der Traum lautet: „Ich war eine Braut, saß auf einem Wagen, kam nach Hause, alles war bekränzt. Ich konnte unter den Girlanden durchfahren. Auf dem Wagen waren Leute, sie fuhren zum Gasthaus, saßen und warteten auf das Essen, bekamen aber nichts. Das genierte mich sehr, wir warteten, auf einmal war wieder nichts. Ich war weder Braut noch wer, jch war nichts, hatte keinen Mann. Ich will auch keinen Mann mehr, ich will nur meinen Mann, den ich früher hatte. Dann reiß aus." Die Pat. fährt spontan fort: „Ich möchte schon wieder heiraten, aber nur meinen Mann ... hat man mich verraten, weil hier ich gefangen bin ... Ich habe meinen Mann besucht, er war im Irrenhause ... Ob man ihm nicht bessere Kost hätte geben können ? Deswegen ist er auch gestorben..." Die Schwester machte ihr Vorwürfe, daß er so elend zugrunde ging ... Sie hätte ihn nach Hause nehmen sollen, aber sie hatte zu wenig zum Eissen. Sie habe Gewissensbisse. Vielleicht wäre er gesund zu Hause geblieben ... Sie macht sich furchtbare Vorwürfe... (Die Pat. beginnt zu weinen.). Aus den Einfällen zum Traum: „Komisch es war kein Mann dabei.“ Mit 17 Jahren hatte sie eine unglückliche Liebe. Ihre Jugend war sehr traurig. - In den nächsten Tagen klingt die schnippische Heiterkeit ab, die Pat. singt viel. Vom Mann spricht sie mit entsprechender Trauer. Am 14. IX. konnte sie geheilt entlassen werden. Defekte irgendwelcher Art bestanden nicht. Sie hatte Kritik und entwickelte vernünftige Zukunftspläne.

Die Pat. war nach der Entlassung zu Hause ganz unauffällig. Ungefähr am 20. IX. 1920 begann sie wieder Zeichen geistiger Erkrankung zu zeigen: Sie blickte in die Sonne, sah dort die Mutter Gottes und ihren verstorbenen Mann. Verweigerte aus Angst vor Vergiftung die Nahrungsaufnahme. Sie wurde reizbar, stritt fortwährend mit anderen Frauen. In letzter Zeit schlaflos bei starker Abmagerung. Selbstbeschuldigungen. Sie klagt sich des Ehebruchs an. Sie hat vor der Internierung zirka 10000 Kronen vergeudet und ließ sich 4000 Kronen entlocken. Im Sprechzimmer geordnet, deprimierter Gesichtsausdruck. Weiß genau das Datum ihrer Entlassung, sei hier ,durch die Leute", ,ich soll gestohlen haben". Sie weiß nicht, wer das behauptet hat, ,vielleicht die Frau Luger". „Mein Mann hätte das Leder gestohlen, darum sitzen wir zusammen im Irrenhaus." Der Mann sei im Irrenhaus gestorben. „Heute ist er nimmer gestorben, heute ist er aufgestanden." (?) ,Schon länger, ich hab ihn dreimal begegnet." Das alles ziemlich affektlos vorgebracht. Bei manchen Leuten war das jüngste Gericht, nicht bei

1) Der Mann der Pat., der an Lues cerebri litt, wurde aus der Klinik in die Iandesirrenanstalt verlegt und ging dort zugrunde. 
allen, sie weiß nicht, wieso das komme. Als zwei Ärztinnen zufällig hinzutreten. „Diesen Frauen hatte ich die Haare genommen ?" (?) „Ich kenn sie nicht näher, Doktorinnen sind es halt; das sagt mir mein Gewissen ..." Sie sei gerichtet, habe viel Schlechtes getan, gestohlen, gemordet, geraubt, geplündert, saufe. (Was noch ?) „Den Männern den Kopf verdreht.“ „Wieso weiß ich nicht.“ Lächelt. „Leute zum Narren gehalten." Beginnt täppisch zu witzeln. „Sind alle, die da sind, Treppen?" Sie sei dumm und deswegen im Irrenhaus. Die Pat. ist vorubergehend heiter, fast ausgelassen, dann wieder traurige Miene. - Beim Examen sitzt sie meist ruhig, dann ändert sie mit einem Ruck die Stellung, knüpft eine kurze Bemerkung an die Vorgänge der Umgebung. Die Antworten auf Fragen meist prompt und sinngemäß. Witzelnde Ablenkung auch jetzt häufig. Sie habe ihren Mann mit Gift umgebracht, weil sie ihn nicht wollte. Sie wollte immer andere Männer... viele Männer. Dann wieder, ,ich habe ihn doch nicht umgebracht", sie sage es nur, weil die Leute es sagen. Vielleicht hat ihn seine Schwester vergiftet. Sie kann es nicht behaupten (sie erzählt dies nur mit Widerstreben!). Es werde gesagt, daß Sie Kinder umgebracht habe, Sie habe im 17. und 18. Lebensjahr im Findelhaus geboren ... Dann: Vor der Ehe habe sie kein Verhältnis gehabt. „Das geht niemandem etwas an." Am 2. X. Sie sei lustig ... man dürfe es nicht sein, die Kinder schlagen sie - (Kinder ?) , die großen ... die Pflegerinnen, alle sind heut Kinder ... sie und ich auch, mein Mann auch.“ „Wir sind alle Kinder Gottes dumme Gedanken hab ich so trüb - trübes Wasser. Man sagt, man habe meinen Mann vergiftet;" sie selbst hätte es getan. Es sagt dies ihr Gewissen, ihr Herz. „Haben sie ein Herz, sie haben es gewiß verschenkt ihrer Frau, ich bin schon wieder ein Narr." Die Pat. ist bewegungsarm, spricht aber in heiterem, etwas affektiertem Ton, dabei abspringend, zahlreiche Klangassoziationen. „Der Mann lebt jetzt wieder. Er ist doch gestorben. Heut irrt man so viel. Er hat auch so schöne Augen wie Sie. Er war auch ein Narr, ich auch, zwei Narren passen gut zusammen." (Zwischen Ernst und Scherzen schwankend.) Jetzt sah sie ihren Mann in W. Wann es war, weiß sie nicht. Zuerst war sie närrisch - (abspringender Gedanken. gang, banale Assoziationen, erzählt von einem Weg, von der Familie, erzählt ideenflüchtig von Alltagserlebnissen.) Der Mann sei auferstanden, gesprochen habe sie nicht mit ihm ...(?) Sie habe einen dummen Traum gehabt. „Ich sah zur Sonne, es tat mir nicht weh in den Augen, ich fing zu beten an. Es war eine Kugel, die wurde immer größer und weißer, ich kniete nieder und schickte Kinder um eine Leiter, sie kamen nicht, ich bekam Angst. Ich fuhr nach Hause, das Wagerl fiel um, ich begegnete den S.-Mädchen, ich sagte: die Sonne haben sie gesehen? Ich bekam dann nicht mehr so viel Angst, weil sie sagten, sie hätten die Sonne auch gesehen." Die Pat. vermengt ideenflüchtig Traum und Wirklichkeit. Eine Reihe weiterer Unterredungen verlief in ähnlicher Weise. Inhaltlich meist von ihrem Manne handelnd, der wieder auferstanden sei. Oder Beeinträchtigungsideen, man beschuldige sie, sie habe ihm das Leben genommen. Auch Selbstvorwürfe. Dabei ideenflüchtiges Abirren. Häufig dialogisiert die Pat. mit sich selbst. Sie schwankt zwischen Witzeln und Trauer. Die Heiterkeit überwindet immer wieder die Traurigkeit. Sich selbst überlassen ist sie meistens ruhiger. Doch kommen auch hier Zeiten, in denen sie bewegungsreich ist, schwätzt allerhand, treibt Schabernack. Am 21. X. in der Vorlesung ist sie exzessiv heiter, schlägt auf den Tisch, unternimmt Angriffe auf die umstehenden Personen, imitiert in grotesker Weise den Vortragenden, schneidet Gesichter, lacht viel. Anfangs verweigert sie jede Auskunft, dann beginnt sie in ideenflüchtig verworrener Weise ohne Unterlaß zu schwatzen. Am 24. X. unverändert in die Landesheilanstalt.

Die ausführlichere Darstellung in diesem Falle ist dadurch notwendig geworden, daß die Diagnose ,Manie“ eingehender begründet 
werden muß. Die Patientin erkrankt zum erstenmal mit 24, zum zweitenmal mit 53 Jahren. Die erste Erkrankung beginnt mit einer depressiven Phase, die mit Halluzinationen einhergeht. Sie wird abgelöst von einer manischen. Auch diese zeigt Besonderheiten: Gehörshalluzinationen beschimpfenden Charakters. Die Patientin ist zeitweise eher traurig, sitzt gehemmt da, dann wieder Ideenflucht und Bewegungsdrang. Leider erfahren wir aus der alten Krankengeschichte über die inhaltlichen Zusammenhänge nur wenig. Die beiden jetzt beobachteten Phasen kennzeichnen sich klinisch als Mischzustände. Depressive Inhalte sind stets nachweisbar. Immer wieder handelt es sich um den verstorbenen Mann, der Gedanke an ihn ruft stets eine echte Traurigkeit hervor. Dieser Gedanke taucht aber immer wieder spontan auf, so daß das Gesamtbild den Charakter eines Mischzustandes erhält. Im übrigen überwiegt heitere, witzelnde Stimmung, hierbei ist die Patientin freilich meist ablehnend. Die Erkrankung des Jahres 1920 läßt den gleichen traurigen Inhalt erkennen. Versündigungsideen treten hinzu. Dabei bricht aber immer wieder der heitere Affekt durch, der in der Grundfärbung völlig dem der Phase 1919 entspricht. Die Ideenflucht ist aber eine hochgradige. Der Gedankengang unzusammenhängender. Die Ablenkbarkeit durch die Umgebung ist dabei keineswegs groß. Die motorische Erregung hält sich in recht mäßigen Grenzen. Beziehungs- und Verfolgungsideen, welche sich wieder auf das Verhältnis zu ihrem Mann beziehen, vervollständigen das Bild.

Dieser Mischzustand läßt sich in keine Form pressen. Man kann sogar im Zweifel sein, ob es sich um eine Manie oder um einen Depressionszustand handle. Jedenfalls sind Störungen des Affektlebens das hervorstechendste. Man könnte z. B. bei der Ideenflucht dieser Kranken die Frage aufwerfen, weshalb die Ablenkbarkeit durch Außenreize so gering ist. Warum in der Phase 1920 die Zusammenhänge im Denken so weitgehend gelöst sind trotz geringer motorischer Erregung. Dabei ist auch die Stimmungslage eigenartig. Eine witzelnde Heiterkeit mit Ablehnung, wobei der Gedanke an den verstorbenen Mann immer wieder auftaucht und eine aus den Tiefen stammende Traurigkeit mit sich führt. Es handelt sich hierbei nicht, wie ich ausdrücklich betonen möchte, um jene oberflächlichen Umschläge, welche man bei allen Manischen findet, wenn ihnen ein vermeintliches oder wirkliches Malheur passiert, sondern es ist eine aus der Tiefe strömende Traurigkeit. Mit Recht betont Kraepelin ${ }^{\mathbf{1}}$ ), daß heitere und traurige oder ängstliche Verstimmung keine Gegensätze wären und zeigt Ähnliches auf anderen Gebieten des Seelenlebens. So schreibt er z. B.: „In der Tat kennen wir einige Erfahrungen, die dafür sprechen, daß

1) Lehrbuch VIII. Auflage. 
die Ausdrücke ,Willenshemmung und ,Willenserregung grobe Sammelbegriffe darstellen, die vielfach zerlegt werden müssen ... Raschheit oder Erschwerung des Entschlusses kann bestehen, ohne daß die äußere Willenshandlung erkennbar verändert ist." Auf diese Weise kommt Kraepelin zu der Annahme einer großen Mannigfaltigheit seelischer Einzelfunktionen, die einer schwächeren oder stärkeren Erregung oder Hemmung zugänglich wären. Diese Anschauungsweise geht aber an dem psychischen Geschehen in der Zeit vorbei. Sie beruht auf einer deskriptiven Psychologie ruhender Erlebnisse. Sie berücksichtigt nicht den Fluß der Erlebnisse. Es wäre sofort zu fragen, ob nicht eine Betrachtungsweise, welche seelische Verläufe berücksichtigt, sinnvollere Ordnung bringen könnte in dieses Chaos erregter und gehemmter Einzelfunktionen. Im vorliegenden Falle ist es psychologisch bedeutungsvoll, daß das ganze Bild beherrscht wird durch die Erinnerung an den Mann. Der Affekt der Trauer um ihn muß jedenfalls in der Dynamik dieser Manie eine gewichtige Rolle spielen. Die Phase des Jahres 1919 beginnt mit einem Selbstmordversuch. In der Phase 1920 treten Wahnideen auf, der Mann sei wieder auferstanden, vereint mit Selbstvorwürfen, sie habe den Mann getötet. Es liegt nahe, in der Heiterkeit nur einen Úberwindungsversuch zu sehen. Man kommt nicht aus ohne die Annahme eines besonders leicht ansprechbaren ,Reservoires". Man hätte ferner zu sagen, ob denn nicht die Trauer über den Mann andersartige Erlebnisse decke.

In den letzten Beobachtungen dominierten bestimmte Komplexe. Diese waren in die Manie eingebettet. In der nun erfolgenden sind es nur wechselnde Kränkungen und Beleidigungen, welche von der Patientin erinnert werden. Es sieht so aus, als ob in dieser Manie alles das, was die Patientin an Kränkungen erfahren hat, an die Oberfläche träte.

Fall 7. Marie E., geb. 1891. Zum erstenmal in der psych. Klinik vom 26. VIII. 1909 bis 6. IX. 1909.

Nach dem Parere wurde an der Pat. von ihrem Dienstgeber ein Sittlichkeitsattentat verübt, das Attentat hatte ein gerichtliches Nachspiel. Der Dienstgeber wurde verurteilt. Seither ist die Pat. verworrener geworden, sie spricht und schreibt unzusammenhängend, äußert Selbstmordideen und hat auch derartige Versuche unternommen. In der Klinik spricht die Pat. unzusammenhängend. Sie erwies sich örtlich und zeitlich als unzureichend orientiert. Knüpft im Gespräch an alles Mögliche an, ist ablenkbar. ,Das Mädl soll fortgehen, es wird ihr schlecht, mir ist schon besser, laßt das stehen ... ich sag's nicht vor dem Mädel . . ." Sie erzählt in unklarer Weise, daß sie von ihrem Dienstgeber verführt worden sei, von 200 Gulden, von Vorwürfen ihrer Mutter, von der Krankheit ihres Vaters ... Nach einiger Zeit sagt sie immer stereotyp, sie wolle etwas erzählen ... Sie ist motorisch unruhig, steht auf, tritt zur Türe, verdeckt ihr Gesicht mit den Händen usw. Ist nur für kurze Zeit zu konzentrieren. Sie gibt an, Lungenentzündung und Masern gehabt zu haben. Die Pat. kam ungeheilt in die Landesirrenanstalt. Die Diagnose der Klinik lautete Amentia. Man wird sie ruhig in Manie umändern können. Vom 
17. VI. bis 30. XII. 1919 neuerdings in der Klinik. Sie hatte 1914 geheiratet. Sie war nicht auffällig. 8 Tage vor der Aufnahme in die Klinik begann sie die Wirtschaft und die beiden Kinder zu vernachlässigen. Sie sprach Tag und Nacht. Sie hatte Eifersuchtsideen gegen ihren Mann. Stritt mit den Parteien im Haus. Klagte, sie werde verachtet und verfolgt. Die Geliebte des Mannes habe die Hebamme (als sie vor 15 Monaten bei der Entbindung half) überreden wollen, sie aus der Welt zu schaffen. Sie sollte sich mit einem Rasiermesser das Leben nehmen. Der Versuch wurde verhindert, die Pat. erzählte dann, ein Engel sei erschienen und habe ihr verboten, sich das Leben zu nehmen. Auf dem Polizeikommissariate: Manisches Gehaben, große Gesten, rednerische Betonung, verlangt Gerechtigkeit, Schutz ihrer Person und Ehre. Thre Feindin verfolge sie seit langem, hetze die ganze Welt gegen sie auf. Die Leute auf der Straße wiesen schon mit Fingern auf sie. In der Klinjk zeitlich und örtlich orientiert. Im allgemeinen extrem heiter, doch ist sie zeitweise etwas deprimierter. Sie ist außerordentlich reich an Bewegungen, spricht sehr viel. Sie erzählt zunächst eine Geschichte von ihrem Vater, deren Sinn nicht ohne weiteres klar ist. Die Volkszeitung hätte ihr erst die Augen geöffnet. Kaiser Franz Joseph sei ihr richtiger Vater gewesen. Sie sei hypnotisiert gewesen durch einen Minister Rechnungsrat. Plötzlich leise: „Ich kann nicht so laut sprechen . . . horchen die Leute ?" Berichtet vertraulich lispelnd über die Macht, die sie besitze, von ihrem Vater, dem Kaiser, erzählt dann geheimnisvoll umständlich von alltäglichen Dingen. Sie habe viel gelitten, werde aber nicht verfolgt, es wider nur immer angedeutet, nämlich daß sie Kaiserin werden soll. Alle die Dinge bringt sie ruhig ohne besondere Erregung vor. Sie ist auch heute lustig, könne aber nicht singen, habe Herzklopfen. Schließt die Augen, klagt. Dann unwillig, sie hätte Hunger, sei nicht aufgelegt zum Sprechen. Verlangt nach Hause. In der Nacht sei ein Schatten gekommen, der gesagt habe, es gebe einen Herrgott, dann korrigiert sie lächelnd, nein, er habe nicht reden können, sie habe es nur gedacht, übrigens wolle sie Ruhe, der Ref. solle weggehen. Wie vor zehn Jahren halte man sie zum Narren, sie werde durch das Fenster entfliehen. Sie fühle sich gesund, habe Kraft. Sie verlangt ihre Mundharmonika. Verlangt sie immer dringender, wird zornig, dann lachend, der Ref. halte sie zum besten. Bei der (keinen pathologischen Befund ergebenden) körperlichen Untersuchung beginnt sie zu weinen, möchte nach Hause. Lacht gleich darauf wieder. 21. VI. Erregt, zornig. Ihre Unschuld sei vor Gericht gewesen, mit 16 Jahren habe sie die Periode gehabt, das müsse aufgeklärt werden. Sie habe wegen des Kindes Hunger gelitten. Sie wolle Gerechtigkeit, wolle vor dem Richter aussagen. 22. VI. Die Kreatur müsse krepieren. Man wolle sie nach Steinhof schaffen, Schweigen sei Gold, die Andeutungen genügten ihr. Sie habe zwei Pulver ohne Arzt bekommen, es sei gesagt worden, es sei Aspirin, sie habe aber daraufhin geschlafen. Erzählt umständlich von der Geburt ihres ersten Kindes, verliert den Faden, kommt auf anderes, hat eine erhöhte Aufmerksamkeit für die Umgebung, ist ablenkbar. Die Leute schimpften auf sie, schreiben anonyme Briefe. Die Leute deuteten an, ,die kriegt das Himmelbett, das Mistvieh, die Kreatur". Sie brauche kein Himmelbett, sie lebe auch einfach gut. Die Pat. ist sehr gesprächig, ihre Äußerungen haben etwas Spielerisches, schweift fortwährend ab, macht halbe Andeutungen, die dann unverständlich werden. Der heitere Affekt wird durch kurzdauernde Zornausbrüche und Klagen unterbrochen. Auch in den nächsten Tagen macht sie in ideenflüchtig unzusammenhängender Weise Andeutungen über eine hohe Abkunft. Sie ist extrem bewegungsreich, die Stimmung ist außerordentlich schwankend, die Heiterkeit herrscht vor, daneben Zorn, flüchtige Trauer, Reizbarkeit, Nörgelei. Nach einigen Tagen verschwinden diese Beziehungsideen. In der Folgezeit zeigt sich immer wieder das gleiche Bild. Reizbar, fühlt sich zurückgesetzt, nörgelt. Ideenflüchtig, von Außen- und Innenreizen 
ablenkbar. Putzt sich auf. Flicht Bänder ins Haar, kriecht unter die Betten. Trotz der Heiterkeit als Grundstimmung bringt die Pat. fast immer Klagen und Berichte, wie sehr man ihr Unrecht getan habe. Ihr ganzes Leben wird unter diesem Gesichtspunkte aufgerollt. Sie berichtet immer wieder, man habe ihr ungerechterweise Paraldehyd gegeben. Thr Vater habe Lungendampf gehabt . . . eine Lehrerin habe sich ermordet. Sie und eine andere Pat. hätten einen Auswurf. Man habe sie aus dem Bad geworfen. Sie werde vor Professor P. aussagen. Ihre Kinder bekämen nichts zu essen. Kaiser Karl habe der Großmutter einmal die Hand gereicht. Der Vater sei als Steindrucker herausgestoßen worden. Die Mutter sei mit Rippenfell- und Lungenentzündung im Spital und sei gerettet worden. Der arme Vater habe nur 12 Gulden bekommen, habe aber die Kinder gut erzogen. Springt ab; jemand habe erzählt, sie gehe auf den Steinhof. Erzählt von einem Toten, der sich umdreht, von Spitalserlebnissen. Wollte vor 16 Jahren Doktor studieren, sie hat alle Handwerke mitgemacht. Jammert, daß sie nicht in den gewöhnlichen Park gehen darf. Die arme Erika (ihr Kind) habe viel mitgemacht. Eine Mitpatientin habe gesagt, man solle ihr eine Schale an den Kopf werfen. (Das ist die Wiedergabe des Inhaltes eines Gespräches vom 13. VIII.) Die Pat. ist also nicht nur empfindlich gegen das Unrecht, das sie in der Gegenwart zu erleiden glaubt, sondern durch Erinnerung taucht auch eine Fülle von Situationen auf, in denen sie Unglück oder Benachteiligung erfuhr. Größenideen treten sehr häufig hervor, die Pat. hat ein ungeheures Selbstgefühl. Sie schreibt sehr viel. Gegen Mitte Dezember wird die Pat. etwas ruhiger. Vor der Verlegung in die Landesirrenanstalt neuerlich heftige Erregungszustände.

Man gewinnt zumindest in ausgedehnten Strecken dieser Erkrankung den Eindruck, es steige vorwiegend unangenehmes Erleben in der Manie aus der Erinnerung auf. Und dieses unangenehme Erleben sei ein Weckruf an die Heiterkeit, welche über dieses Unangenehme sich hinwegsetzen will. Es waren keine bestimmten Komplexe, die dabei besonders hervortreten. Eine eingehendere Untersuchung nach dieser Richtung war der Sachlage nach nicht möglich. Es ist beachtenswert, daß in diesem Falle während der ersten Frkrankung die Ideenflucht bei mangelndem Affekt zu einer solchen Zerreißung des Gedankensganges führte, daß die Diagnose auf Amentia gestellt wurde. Bei der neuerlichen Erkrankung eröffnet sich ein Zustandsbild, das paranoische Anklänge zeigt. Dann erst tritt das typische Bild reizbar nörgelnder Manie in den Vordergrund.

Allen bisher berichteten Fällen ist es gemeinsam, daß nicht überwundene traurige Erlebnisse in der Manie bestehen bleiben, in sie hineinragen, die Manie ändert an ihnen nichts, sie treibt nur neben ihnen die Heiterkeit, Ideenflucht usw. hervor. Im Falle 6 findet in der Phase des Jahres 1920 allerdings eine Komplexbearbeitung in wahnhafter Weise statt, der betrauerte Mann erfährt eine Wiederauferstehung und im Falle 1 erlebt die Patientin die in Wirklichkeit mißglückte Vergewaltigung als geglückt. Immerhin steht in diesen beiden Fällen die bewegungsreiche Heiterkeit nicht in unmittelbarer Beziehung zu der Problemlösung. Anders bei den nun folgenden Beobachtungen. 
Der erste dieser Fälle gehört nun allerdings klinisch vermutlich nicht zum manisch-depressiven Irresein, sondern zur Schizophrenie. Das psychische Zustandsbild ist aber dem der Manie so ähnlich, daß es doch berechtigt erscheint, den Fall hier mitzuteilen.

Fall 8. Margarete V., 37 Jahre alt, in die psychiatr. Klinik aufgenommen am 8. X. 1920.

Familienanamnese (Angaben der Mutter): Großmutter der Pat. im Klimakterium an einer Psychose erkrankt. Vater und zwei Brüder des Vaters endeten durch Selbstmord. Der Vater nahm sich wegen einer unglücklichen Liebe das Leben. Er starb, als die Pat. drei Jahre alt war. Die Pat. war als Kind sehr ener gisch und unfolgsam. Späterhin war die Pat. reizbar, exaltiert, starrsinnig. Sie wechselte trotz großer Begabung häufig den Beruf. Sie hatte überspannte Ideen. In Anstalten war sie nie. In dem jetzigen Zustand ist sie erst seit einigen Wochen. Vorher war sie in Budapest politisch tätig, war als Kommunistin eine Zeitlang in Haft. In früherer Zeit manchmal verstimmt. Selbstmordabsichten hatte sie nie. Mit ihrem Mann lebte sie in unglücklicher Ehe. Am 8. X. erschien sie in der Portierloge eines Theaters mit Föhrenzweigen und einem Brief an den Schauspieler Karl M. Dieser hatte schon früher von der Pat. schwärmerische Briefe erhalten.

Bei der Beobachtung in der Klinik erwies sich die Pat. als klar, geordnet. Zeitlich und örtlich ist sie orientiert. Sie ist heiter, vielgeschäftig. Im Ideengang abspringend. Sie ist bewegungsreich. Sie erscheint von Glücksgefühl durchtränkt zu sein. Sie habe so viele Gedanken im Kopf, daß sie nicht alle zu Papier bringen könne. (Sie hat einen Pack Briefe und vier vollbeschriebene Hefte mitgebracht.) Vor 11 Jahren habe sie ihren Mann nur aus Mitleid geheiratet. Sie lebte schlecht mit ihm. Beim Verkehr mit ihm verspürte sie nur Fkel. Er war ihr gegenüber brutal, schlug sie oft, er unterdrückte sie immer. Sie fühlte einen Druck am Herzen. Sie fühlte sich sehr unglücklich. Im Februar 1920 trat in ihr Leben Karl M. ein. Da kam die Verwandlung, die seelische und physische. Sie blühte auf, die Brüste wurden jungfräulich, sie fühlte sich wie eine Braut, alle bemerkten es, sie entbrannte in demütiger Liebe zu ihm, es war so wie wenn ein telepathischer Strom von ihm ausginge. Sie spürte ihn wie Stiche am Herzen und auch die Gebärmutter öffnete und schloß sich. Diesen Strom spürt sie, wenn sie nur an ihn denkt oder seinen Namen nennen hört. Er sei für sie alles, ein Ehemann, ein Vater. Sie wünsche von ihm ein Kind zu haben. Dieses wüde sie dann Dieudonné nennen. Sie stehe mit ihm in innerem seelischem Kontakt durch Blicke. Wenn sie ihn kränken will, dann wird er krank. Er liebe sie seit dem Moment, wo seine Frau ihm die eheliche Treue brach. Er und sie haben sich seit ihrer Befreiung - ihr Mann habe in die Scheidung eingewilligt - gefunden. Zweimal habe er sie geküßt. Den seelischen Druck des Kusses habe sie lange Zeit nachher noch gespürt. Die Frau Karls war eifersuchtig auf die Pat. Der Sohn Karls hängt mit Liebe an ihr, als ob sie die Mutter wäre. Leidet er, so spürt sie sein Leiden physisch am eigenen Körper.

Ihren Vater hat sie im dritten Lebensjahre verloren, er soll Selbstmord be gangen haben. Die Mutter verbot den Kindern, von ihm zu sprechen. Sie bezeich. nete ihn als treulosen, schlechten Menschen. Erst am Wendepunkt ihres Lebens begann die Pat. über ihren Vater nachzudenken, erkundigte sich über ihn bei der Pflegemutter, erfuhr, daß er ein edler Mensch, ein Dichter und Sänger war. Als sie Karl kennenlernte, suchte sie den Vater in ihm, sie wollte sich mit Willen der Frau und der Kinder von ihm adoptieren lassen. Zwischen ihrem Vater und Karl besteht eine sehr große physische und seelische Ähnlichkeit. Die Frau Karls ist ihrer Mutter ähnlich, falsch, liebeheuchelnd. Werfe ebenso wie ihre Mutter den Schein des Schlechten auf ihren Mann. Es ist sicher, daß ihre Mutter auch eine 
Ehebrecherin war. Ihre Mutter habe auch ein Kind der Pat., das sie als 19jährige von einem Studenten hatte, zugrunde gehen lassen. - Sie fühle in sich eine Bestimmung, etwas Gutes zu tun. Schon als 15jähriges Mädchen fühlte sie, daß sie das Mittel war, durch welches man die Elektrische in Wien eingeführt habe. Sie sei ein Problem. Sie würde schon darauf kommen, wie die Zusammenhänge seien. Auch habe sie die Bestimmung, Verbrecherkinder zu erziehen. Durch ihren Beruf als Erzieherin habe sie erfahren, daß die Kinder nicht schlecht seien, daß man sie zu arbeitswilligen Menschen machen könne. Sie habe auch die Bestimmung, die Gesetze der Kirche und des Landes zu reformieren. In den letzten Nächten sei ihr von ihrem Stern, der jede Nacht ins Zimmer leuchte, eingegeben worden, die zehn Gebote zu reformieren, das habe sie auch getan. Diese Bestimmung fühle sie in sich, weil sie nicht sinnlich sei, sie wolle zwar mit Karl vereinigt sein, aber das sei keine Sinnlichkeit, das sei die Weiblichkeit, der natürliche Trieb zum Zeugen. Alle Tiere hätten sich immer von ihr angezogen gefühlt, es sei die ausstrahlende Liebe in ihr, der ewige Zeugungstrieb. - Karl sollte eines Tages mit einem schweren Rucksack mit einem Rad von ihr zuruckfahren, sie bat ihn, er solle mit der Bahn fahren, er tat es aber nicht. Als er dann wegging, mußte sie sich ins Bett legen, sie hat direkt Schmerzen verspürt, im Rücken die Last, die ihn gedrückt hat.

Alle diese Gedanken werden teils mündlich, teils schriftlich in immer neuen Variationen gebracht, die Pat. ist dabei sehr unruhig, tätig, abspringend, erregt. Aus ihren Aufzeichnungen sind folgende Sätze beachtenswert: „Unser größter Schatz ist unser Wille, mit dem wir zeugen können und das Gezeugte genießen können." „Ich weiß, daß die Elektrizität eine Energie, eine Naturheilkraft ausströmt, um zu heilen." „Glaubt ihr jetzt, daß ich wahrhaftig Eure Mutter bin?" „Ich wollt es immer sein ... jetzt endlich nach 37 Jahren des Leides hab ich mein Kind geboren. Es gehört euch allen. " „Weg mit der Sinnlichkeit." Dabei ist die Pat. in den ersten Tagen nach ihrer Aufnahme sehr erotisch. Duzt den Arzt, bezeichnet ihn als Karl, nicht weil er jenem Karl, sondern einem anderen Karl, einem Jugendfreund ähnlich sehe. In einer Vorlesung erklärt sie sich als die Mutter aller. Der Sternenhimmel sei Zeuge. Die Idee, welche sie in den Tagen nach der Aufnahme, besonders beschäftigt, ist folgende (nach ihrer eigenen Niederschrift): „Ich wußte, daß ich mein Glück 9 Monate in mir herumtragen mußte, dabei leiden mußte, um es im 10. Monate zu gebären. Ich selber wurde wiedergeboren. Am ersten Tag der Begegnung ging die Zeugung vor sich. Am 1. X. waren 9 Monate um, ich fühlte meine Entbindung nahen - ich hatte ein erhebendes Gefühl, ganz überirdisch, war ganz der Welt entrückt, lebte nur dem gebärenden Glücke - der Liebe. Ich weiß bestimmt, daß die Geburt, resp. die Geburtswehen am 1. X. einsetzten, denn ich fühlte am Rücken, am Kreuze Schmerzen genau so wie bei Geburtswehen - nur etwas schwächer. Die Wehen kommen und vergehen. Damals erblickte ich meinen Stern zum erstenmal, ich mußte an die Geburt Christi denken, an die drei Könige. Ich fühlte deutlich, daß ich direkt vom Christus abstamme ..." Sie betont immer wieder, sie sei mit sich selbst schwanger gewesen und habe sich selbst wiedergeboren. In den folgenden Tagen wird sie immer erregter. Sehr bewegungsreich. Höchstes Glücksgefühl. „Ich bin selig, im siebenten Himmel." Sagt zu einem eintretenden Arzt: „Bist du der Wunderdoktor aus Dresden, der die Menschen heilt, indem er ihnen die Genitalien besprengt." Große Reformpläne. Formuliert neue 10 Gebote. Höchstes Selbstbewußtsein. Abspringend im Ideengang, doch kommen immer wieder die gleichen Grundideen zurück. Leicht in Zorn zu bringen. Am 20. XII. stellt sich die Pat., die von der Klinik in die Landesirrenanstalt verlegt worden war, in der Klinik vor. Sie ist verstimmt, traurig, aber zugänglich. Si* soll zu ihrem Mann nach Budapest. Zu Beginn der Erkrankung habe sie sich eingebildet, er sei vom selben Geschlechte und es sei Blutschande, mit ihm zu ver- 
kehren. Zu Karl habe sie eine Neigung gehabt. Er auch zu ihr. Sie wollte ihn wirklich heiraten. Die Ausdrücke Fruchtbarkeit, Mutter aller usw, seien geistig gemeint gewesen . . J Jetzt sei sie ängstlich, mutlos, sie könne nicht denken, sie sei sicherlich unheilbar. Sie äußerst Selbstmordideen. Sie ist eigentümlich traurig, zeitweise ein steifes Lächeln. Hat noch immer etwas pathetisch, hochtrabend Geziertes in ihrem ganzen Wesen.

Zur Differentialdiagnose: Das Pathetisch-Geschraubte ihres Wesens, die merkwürdige Gestaltung der Wahnideen läßt die Diagnose einer Schizophrenie als wahrscheinlicher erscheinen ${ }^{1}$ ). Die Erkrankung entwickelt sich aus einer unglücklichen Ehe heraus, die als schwerer Druck empfunden wird. Sie leistet der Patientin die Vereinigung mit dem Geliebten, seinen vollen geistigen Besitz, die Wiedergeburt und das Bewußtsein, die geistige Mutter aller zu sein. Daß der Geliebte nur den Vater vertritt, geht aus den Äußerungen der Patientin klar hervor. Die manische Phase (der Schizophrenie?) ist also eine völlige Erfüllung ihrer Wünsche, eine Lösung aller ihrer Fragen. Das Hochgefühl, das gehobene Selbstbewußtsein ist unmittelbar aus dieser Erfüllung der Wunschtendenzen heraus verständlich. Hier ist es also der befriedigte Ödipuskomplex, der die Manie kennzeichnet, der ihr zugrunde liegt.

Nun zu einem sicheren Fall von Manie im Verlaufe einer zirkulären Psychose.

Fall 9. Käte Lau, geboren 1879, in der Klinik vom 4. V. 1920 bis 3. VI. 1920.

Die Pat. hatte bereits 4 depressive Phasen und zwei manische. Während der zweiten Depression Suicidversuch, bei dem sie vom fünften Stock hinuntersprang (1903). Doppelter Schädelbruch, doppelter Beckenbruch, Bruch der Unterarme, Bruch des Nasenbeines. Ageusie, Anosmie. Im Januar 1920 kündigte sie in dem Bureau, wo sie als Kontoristin beschäftigt war, da sie sich bei einer Gehaltsaufbesserung benachteiligt fühlte, seither deprimiert. Die Arbeitslust ist aber nicht geschwunden. Die Pat. fühlte sich auch nicht gehemmt. Klagen über Schwindel und Kopfschmerzen. Am 26. III. 1920 in die Heilanstalt ,Theresienschlössel". Daselbst in den ersten Wochen mäßige Depression. Ende April begann sie inhaltsleere, aber lange Briefe an den behandelnden Arzt Dr. L. zu schreiben. Einen Nachmittag lachte sie stundenlang. Hörte eine Stimme: „Nur nicht zu stolz Fräulein Lau, es könnte Ihnen schaden. “ Die Briefe wurden im Charakter immer mehr manisch. Am 3. IV. besuchte sie den Arzt zweimal in seiner Wohnung. Machte Anspielungen. „Bin ich's oder werd ich's ?" Schließlich, sie müsse sich Klarheit und Wahrheit verschaffen. "Lieben Sie mich Herr Doktor oder nicht ?" „Weil wir sich so gerne haben." Will den Arzt umarmen, hörte Stimmen: „Ich hab mein eigenes Ich verloren, ich bin wie ein Hund zu führen, so wie die Schauspielerin, die in Hietzing gewohnt hat. Ich werde von weißen Pferden verfolgt. Ich hab sie da unten in der Gasse gesehen, besonders ein weißes. Zuerst immer zu zweit, dann eines das wie toll, als weiße Braut ... ob die Schwestern wissen ?" "Ich kanns gar nicht glauben ... " Die Pat. hatte im ganzen Hause auf alle Zetteln Gedichte, Sentenzen usw. geschmiert.

Die Pat. ist klar, geordnet, vollkommen zeitlich und örtlich orientiert. Sehr gesprächig, etwas gereizt. Sie sei seit Januar krank, sie habe einen Bureauposten

1) Daß derartige „Diagnosen" nur einen relativen Wert haben, ist mir bewußt. 
verlassen müssen, weil sie der Chef erniedrigt habe, er hat ihr nur niedere Posten gegeben - das habe sie sehr gekränkt. Sie konnte ihre Arbeit nicht leisten, war schlaflos und gereizt. Januar 1920 verließ sie den Posten. Der Zustand verschlech. terte sich immer mehr, sie meinte zu Hause, daß sie allen Leuten im Wege sei, ihrer Familie. Thre Schwester, die selbst sehr unglücklich war, suggerierte ihr immer die Selbstmordgedanken, sie sprach immer, wenn nur die Grippe käme; sie kämpfte mit dem Gedanken und fühlte sich sehr schlecht. Sie kam im April ins Theresienschlössel, dort spürte sie in sich einen Impuls, Briefe und Gedichte an den Arzt zu schreiben; er habe ihr Vertrauen erworben, deshalb kam sie in Verdacht, daß sie in ihn verliebt sei. Sie habe immer den Eindruck gehabt, sie sei eine Hellseherin, sie könne von den Augen der anderen lesen, sie könne durch ihre Kraft und Berührung ihren Gemütszustand den anderen Menschen suggerieren; so geschah es mit einer Frau, die sie unter den Arm nahm und der sie durch die Berührung ihre Nieder. geschlagenheit mitgeteilt hat, die Frau stürzte dann zu Boden. - Es gehe in ihr so Sonderbares vor, ihre Stimmung schwanke immer zwischen hoch und nieder, sie sei an der Grenze der Gesundheit und des Irrsinns. - Sie habe ihr Herz an den Herrn Dr. L. verloren, das kränke sie so, weil sie es nicht wisse, ob er es fühle. Sie habe Stimmen von Plafond gehört, die ihr zuriefen, ,sei geduldig, sonst könnte dir das schaden. “ Eines Tages hörte sie von der Straße jemanden rufen: die Schwester werde sie abholen, sie ging nunmehr durch das ganze Gebäude, ,überall fand sie Fallen aufgestellt, aber keine Schwester, zwei Paar Schuhe, drei Paar Schuhe, das ist ein Stück, das gespielt wird, ich sah Gruben, wer eine Grube gräbt, der fällt selbst hinein, ich traf Schalen von Glas, Schalen bedeuten Glück, in der feinsten Lyrik, Blumen fand ich, ging dann weiter, bis ich Herrn Dr. L. getroffen habe, dann kam ich hierher. Ich schrieb immer Briefe, ich mußte es tun, es war meine geistige Nahrung, ich folgte der Stimmung in mir." (Pat. ist sehr labiler Stimmung, bald weint sie bei dem Gedanken an das Unglück einer Pat. aus Mitgefühl mit ihr, bald lacht sie. Immerfort wechselt sie das Thema, geht von einem Detail ins andere. erzählt es weitschweifig, gerät auf Nebenwege, mengt eine Menge Sprichwörter ein, reimt.)

Die Stimmung, erzählt sie, war die ganze Zeit sehr schwankend, einmal fuhlte sie sich unglücklich, dann wieder glücklich. In jedem Momente war es anders. Sie kam hierher ins Spital, wurde mit einem Mädel zusammengebracht, die wurde ihr zur „Probe“ gestellt, sie sollte ihre Gedanken herauslesen, um zu erfahren, ob sic wirklich krank sei, sie sollte sie retten. - Hält sich die Ohren zu, mit der Begründung, die Stimme einer Mitpatientin rege sie auf. Weil sie sich nicht auskenne, ob es Wahrheit sei oder nicht, sei sie gradezu krank. Sie wolle die Stimme nicht hören, sie wolle sich nicht der trügerischen Hoffnung hingeben, daß es Wahrheit sei, was ihr Herr Dr. L. zugeflüstert hat, daß er sie gern habe. Sie habe sich für ihn in der Krankheit aufgeopfert. „Eine schöne Menschenseele zu finden, ist ein Gewinn, ein schönerer Gewinn ist sie zu erhalten, das schönste und schwerste jedoch der, eine, die schon verloren war, zu retten. "- Sie schreibe ununterbrochen, es komme ihr so leicht, es komme aber nie so zum Ausdruck, „Gedankenstrich, Ausrufszeichen, Beistrich." - Schon als Wickelkind war sie - so berichtet sie - ein un. ruhiges, vielschreiendes Kind, mit 6 Jahren hatte sie immer Angst vor der Schule, war sehr überreizt. Im 9. Lebensjahr kam über sie die erste Melancholie, sie dachte, daß sie nichts könne, die Beichte war ihr unendlich krankhaft schwer. Sie hatte Angst, daß sie in der kurzen Zeit manches vergesse und so sündige. Bei der Beichte beantwortete sie ängstlich die Fragen immer mit, ,ja “. Sie war ganz niedergeschmet. tert, als sie bei einer späteren Beichte der Pfarrer fragte, ob sie schon mit dem an. deren Geschlecht Unkeuschheit geübt habe. „Wenn es der Fall ist, dann komme ich unter die Schweine, er sollte sagen zu ihm, da manche Pfarrer sich wie Schweine benehmen." 
Sie bemerke: wenn ein Mensch mit dem Arm zucke, so habe das zu bedeuten, „sage die Wahrheit". ,Das ist die Kraft des Hypnotiseurs, im Moment, wo man aus der Rolle fällt, gibt es einen Zuck."

Stimmt in den Gesang einer Mitpatientin ein, hört die Stimme des Dr. L., die Stimme suggeriere ihr etwas. Erzählt dann wieder von jenen Beichten.

Vor Verwirrtheit, da neben ihr ein anderes Geschlecht Rudolf K. kniete und sie in Gedanken unkeusch war, konnte sie nicht beichten, sie ging aus der Kirche, kam in die Nähe eines Gasthauses Karl F. zur lustigen Wienerin, daneben stand das Wort „Fest", sie sollte nicht hinschauen, sie schaute doch hin und darüber war sie sehr unglücklich, sie fühlte, daß es eine Todsünde war, sie beging die zweite Sünde, die erste, daß sie Karl geküßt hat, die zweite, daß sie sich umgeschaut hat auf die Worte, und die dritte, daß sie den Namen Gottes eitel genannt hat. Zu Hause betete sie, wollte mit den Kindern nicht spielen. Am nächsten Tag kam die Kom. munion, die Schwester, die für sie ein Muster war, die ihre Führung übernommen, ging mit zum Altar, während des Zeremoniells zerbiß sie den Leib des Herrn und glaubte dadurch eine Todsünde zu begehen. Nachher gab sie sich dem Leben hin und freute sich. - Bis zum 18. Lebensjahr war sie normal. Mit 18 Jahren dachte sie nur an Selbstmord. Da kam die erste Krankheit, der Irrsinn, sieglaubte als Schneiderin nichts leisten zu können, sie kaufte sich Äther. - Ihr Wesen hatte sich ganz verändert, sie war sehr traurig, weinte viel. Der Zustand dauerte einige Monate, bis zum 23. Jahr arbeitete sie gut, war abwechselnd heiter und traurig, die Leute behaupteten immer, sie habe ihren Beruf verfehlt, sie sollte Schauspielerin werden. - Dann kam wieder der Irrsinn mit dem Gedanken, daß sie nichts zu leisten vermöge, sie stürzte sich vom 5. Stock und lag dann auf der Klinik. Nachher erholte sie sich wieder, blieb bis zum 31. Jahre gesund. Da starb ihre Mutter und ihr Vater, den Tod hat sie sich zu Herzen genommen, sie wollte sterben, erwartete den Tod. Sie war krank, stand bei Prof. Stransky in Behandlung. Die Mutter starb in Steinhof an Gehirnblutung.

1903 in Klosterneuburg in der Anstalt, schrieb sie ihre Krankengeschichte, liebte den Prof. B., ihren Zustand schildert sie mit den Worten: „Himmelhoch jauchzend, zu Tode betrübt." Sie putzte sich wie ein Narr.

Der Traum von der Brautnacht habe sie oft verfolgt, er wiederholte sich, er verfolgte sie bis zur nackten, puren Wirklichkeit. Die Brautnacht verbrachte sie immer mit einem Ideal, dem schönsten Mann. Sie habe niemals mit jemandem verkehrt, weil ihr nicht ein Mann bestimmt war. Sie liebte den Prof. B., der ihr die Liebe beantwortet hat.

Kehrt zur Gegenwart zurück.

Eine Pat., die traurig saß, wurde von ihr angesehen, sie erholte sich darauf. Die Pat. flüsterte ihr ein; sie suggerierte ihr, sie solle gesund sein, sie hat den Takt dazu gegeben - sie kann überhaupt auf diese Weise helfen.

Sie habe sich immer vorgestellt, das größte Glück sei doch, ein Kind mit einem geliebten Mann zu haben und daran zu sterben. Den Traum von der Brautnacht und der Mutterwerdung hatte sie nach dem Sturz, er wiederholte sich oft, sie fühlte genau, wie sie das Kind gebar und neben ihr stand der Mann, der sie tröstete, um ihr die Leiden des Gebärens zu erleichtern. Es war alles so deutlich wie eine Halluzination im Schlaf. Diese Träume hatte sie im natürlichen Leben und nicht im Irrsinn.

Pat. ist andauernd heiter, singt zeitweise, ist ideenflüchtig, mengt Sprüche, Verse, reimt.

Im Traum spürte sie eine Angst vor dem gewissen Etwas in der Brautnacht. Sie habe nie verkehrt, weil sie nie einen gewöhnlichen Arbeiter wollte, sie strebte nach etwas Höherem, nicht umsonst träumte sie im Theresienschlößl vom Fliegen 
und vom Verfolgen durch wilde Pferde, darunter war immer ein weißes. Sie würde als 40 jährige Frau nicht als strahlende Jungfrau erscheinen, sondern in einem gewöhnlichen Kleid aufs Standesamt gehen. Das weiße Pferd war sie, die wilden Pferde waren schwarz, zuerst kamen viele Pferde, dann einige, dann eines, das letzte war das, das ihr helfen konnte, das war der Dr. L., der sie heiraten wird. Die weinenden Stimmen der Mitpatienten sind die Stimmen der Schauspieler, die aufgenommen sind unter Suggestion des Dr. L., die reizten sie und spotteten sie aus, jetzt weiß sie es genau. Auch sie kann suggerieren, hypnotisieren. 13. V. Noch immer erregt ... „Die Leute schauen mich alle an, daß ..." (?). „Weil ich Hypnotiseurin bin, seh ich alle an ... wenn ich nicht den Blick senke, so zittre ich, weil mich alle ansehn ..." (Geträumt ?) ,Weil der Herr Dr. L. heut selber kommt, mich abholen ... ich soll sie ununterbrochen anschauen ... nicht wahr ..." (ist etwas dämmrig, fahrig). (Was sonst ?) „,Das Gefühl im Unterleib . . . in den Füßen, überall könnte ich die Gefühle auslösen, weil ich Hypnotiseurin bin, sage die Wahrheit unter der Hypnose ..." (Was für Gefühle ?) „,Der Herr Dr. L. . ., daß ich hin. eingehöre. Jetzt fängt es schon wicder an von unten herauf. (?)“ „Daß ich unter der Hypnose eines Irrenarztes stehe (?), Dr. L.“ (Geschlechtlich ?) „Ja, ich hab' das wollen gerne selbst auslösen ... wollen, ... dorten ..." (Reibt sich den Bauch.) „Sag' mir die Wahrheit . . . ich brauche nur am Tiseh zu streichen und an die Stirne zu legen ... Sag' mir die Wahrheit ... hast du noch etwas am Herzen. Das ist die Hypnose.“ (Zitternd.) ,Jetzt fängt es schon wieder an, es ist schon wieder eingeschaltet ... Eine Schwester erregt mir das Gefühl ... das ekelhafteste Gefühl... immer hat sie sich entblößt ... Deswegen sag' ich ... ich gehöre zu meinen Geschwistern und zu Dr. L.“ (Als ein Priester vorbeigeht.) ,Weil der Hochwürden vorbeigeht, sehe ich wieder dasselbe. (?) Hypnose sage die Wahrheit. " (Hypnose... Geschlechtlich?) „Nein ... mir ist die Kraft der Hypnose gegeben ... ich hätte mich nicht hypnotisieren lassen, weil man ein willenloses Werk ist. Ich hätte die Hypnose bis zur Starrheit ausgelassen. (Als der Ref. die Pat. zufällig ansieht.) Jetzt haben die Blicke sich getroffen, jetzt kann man schon wieder weiter schreiben ...."

„Der Vater war zu hart, die Mutter zu gut ... Daraus entsteht das Unglück für die Kinder."

Fühlt sich durch alle Blicke beeinflußt. Sie und Dr. L. sind Hypnotiseure. „Dr. L. weiß alles ... Die ganzen Gefühle, welche unter der Hypnose stehen, sagen die Wahrheit, haben die Frauenärzte untereinander ausgelöst. Alle Stimmen strömen mir zu, weil ich und Dr. L. Hypnotiseure sind.“ (Vater hart ?) „Es ist immer dasselbe. Dr. L. weiß alles. Ich kann Wahrheit und Lüge nicht vertragen . . bin Hellseherin, Hypnotiseurin und mondsüchtig . . . Jede Stimme sagt mir genau, was ich zu tun hab' ... . Dr. L. leidet unter meiner Hypnose und ich unter seiner. Dr. I. ist Hypnotiseur und nur meinetwegen hier." (Hyperprosektisch, beachtet die Vorgänge der Umgebung.) „Ich bin als Opfer da.“ (Vater ?) „Der Vater war so grob mit der Mutter ... der Vater wollte nur, daß die Kinder verdienen ... die Mutter hat nur für die geistige Nahrung gesorgt, und deshalb gehen wir durch den Krieg zugrunde. Jetzt ist wieder die Hypnose da." (Wer ?) „Dr. L." „In der Zelle erscheinen die Gesichter von Jugend und Alter" (?) „Es ist ein Flimmern ... Ich hab' alles schon gesagt ... Die Gesichter erscheinen, werden immer geschleudert ... . vom Ältesten zum Jüngsten ... ein Fisch wird gleich ein Vogel ... wird ins Unendlichste geschleudert." Sie zeigt das mit den Handbewegungen ... Sie hat im Schlößl geträumt, daß der Vater von Dr. L. dort ist. „In dem Moment war es ein Herr, dann ein anderer. Die Gesichter erscheinen im Traum, wenn ich das Flimmern hab'." (Warum Zittern?) „Weil der Dr. L. in der Nähe ist." 22. V. Motorisch sehr erregt ... ißt, klopft, geht von einem Sessel zum andern, haut auf 
den Tisch auf. Als der Ref. ein Glas Wasser trinkt ... ,Ah, ein Glas Wasser soll ich auch trinken." (?) „Damit ich Thnen die Sache erleichtere und Sie nicht so viel trinken." (?) „Ich hab' gestern gesehen, daß in deinen Augen Tränen gestanden sind ... weil ich hab' die Mutter zuerst erlösen wollen ... “ Ideenflüchtig. „Menschen und Tier sind alle gleich, jeder muß seinem Trieb folgen . . " Wartet auf Dr. L., der sie abholen soll ... Macht sonderbare Handbewegungen zu einer anderen Pat. „Die möcht' ich auslösen von der Psychose, mit dem entgegengesetzten Blick auslösen." Nestelt sonderbar spielend an ihrem Haar. Geht tanzend im Zimmer hin und her ... mit geheimnisvoll beschwörenden Bewegungen. (Was gemacht?) Geheimnisvoll: „Psychose.“ „Das ganze Nervensystem des Menschen ... daß Mensch zu Mensch gehört, aber nicht einem gewissen Idealismus."

(Zu den Angaben der Pat. ist zu bemerken, daß sie, soweit sie Objektives bringen, durch frühere Krankengeschichten hinlänglich belegt sind. Aus der Jugendgeschichte ist nachzutragen, daß die Pat. bis zum 11. Lebensjahr an Bettnässen litt. Sie hatte besondere Angst vor ihrem Vater, besonders auch, daß er das beschmutzte Bett nicht sehe.)

In den folgenden Tagen immer wieder, sie habe den Dr. L. gerne, er kann sie durch Heirat erlösen, er ist ein hoher Geist. Sie sei Hellseherin und Hypnotiseurin. Sie ist ideenflüchtig. Großer Rededrang, dabei inkohärent. Häufig Stimmen. 14. V. Manisch erregt. „Ich kann es nicht fassen, nicht glauben, es hat ein Traum mich berückt, so liebt er denn unter allen mich arme, erhöht und beglückt ...“ Reicht dem Ref. die Hand. „Wenn sich die Blicke getroffen ... Heute gehen wir alle zusammen nach Hause (Bewegungsreichtum, Hyperprosexie). Gedankenstrich, aber noch nicht heute..." Das Flimmern vor den Augen habe sie immer gehabt ... Sie hat als unsichtbares Medium gehandelt und hat im Gitterbett getanzt. "Warum ich das hab' tun müssen, das weiß ich nicht." (?) „Ich hab' getanzt wie ein Narr, ich glaube, daß ich von heute an gesund bin ... ich bin die einzige, die dem Irrsinn nahe war..." Spricht immer wieder von ihrer Liebe zu Dr. L. . . Bezeichnet den Ref. als Bruder des Dr. L. 16. V. Ist zusehends verworrener geworden. Heíter, selbstbewußt. Zeitweise etwas dämmerig. „Kann jeder Arzt hypnotisieren. Du kannst es nicht ... bist aber verheiratet ... Er (Dr. L.) hypnotisierte die Pat., er kam wie ein Mann zu den Pat., ich hab' ihm geholfen, die Stimmen auslösen, die er mir immer bietet. (?) Seine Stimmen ..." „Er hat Schauspieler werden sollen, ist aber Arzt geworden." (?) „Ich hab' das gefährliche Alter gefühlt, es ist aber nicht nahe. Er und ich sind große Kinderfreunde ... im Traum erschien mir, ich möchte aus Liebe zu einem Mann bei der Geburt sterben." (Als eine Mitpatientin sich auf einen Mantel legt, sagt sie.) „Da legt sie sich schon auf den Martel, sie will und muß sich austoben ... Verse ... Thn trieb es fast zum Wahnsinn, weil er glaubte, er hätte mit dem Eheleben ein Unrecht . . . Ich hab" immer nur mit der Uhr in der Hand durch das ganze Land ... "Bezeichnet plötzlich eine Mitpatientin als ihre Mutter (?) „Weil ich die Mutter am meisten schätze. Sie muß so lange meinen Blicken folgen, als sich Mutter und Kind finden ..." (Zum Ref.) „Wir stehen unter der Hypnose Bruder Schwester." (Bezeichnet den Ref. immer als Bruder von Dr. L.) Die Pat. macht sonderbare Bewegungen, wie beschwörende Tanzbewegungen angeregt durch die Bewegungen einer anderen Pat. (Es ist der Fall 1 dieser Mitteilung) und sagt: „Die macht Bewegungen, weil ich mich bewege. “ Dann ,,jetzt ist sie wieder traurig, jetzt liegt sie wieder dort wie die Lau“. (Als die andere Pat. singt.) „Um das Mädchen von seiner Hypnose (des Dr. L.) auszulösen . . . da müssen nur alle nach meinem Herzschlag . . . (Was für Kraft hat Dr. L. ?) Ich hab' an Onanie gelitten. . . er dachte, er müsse mich erlösen." (Die Pat. Z. ruft Anna.) „Da ruft er schon wieder, er möchte, daß ich erlöst werde ... Ich muß nachschauen, daß mein Blick bleibt, denn, wenn die 
Augen hinaufgezogen werden, dann führe ich den Tanz aus bei der Mondnacht." (Haben sie auf andere Einfluß?) Beginnt einer anderen Pat. nachzusingen. Winkt mit sonderbaren Gesten der Pat. Z., man gewinnt den Eindruck, daß sie versucht, auf diese Weise die anderen Patientinnen zu beeinflussen.

I. VI. Immer unruhiger. Unrein. Liegt auf dem Bauch. Rhythmische Bewegungen des Kopfes gegen den Polster, schiebende des Beckens. „Ich löse andere Leute aus." Dann wieder andere rhythmische Bewegungen. (Was ist los ?) „Hypnotisieren ..." (Wozu die Bewegungen?) "Weil mir das das Innere sagt..." Sie ist sehr unrein. Läßt Urin unter sich.

2. VI. Macht schiebende Mundbewegungen: „Ich werde gleich fertig werden, habe die Blicke schon getroffen ... Vis-à-vis schauen, dann werde ich ausgelöst von der Krankheit.“ (Was spülen sie denn aus ?) „Die Krankheit.“ (?) (Verzieht die Lippen.) . . .,Beginnender Irrsinn . . . Genie und Irrsinn . . . man muß mich ausspülen lassen, denn ich habe mich so viel für die anderen geopfert. In der rechten Nasenseite war der Geruch noch.“ (?) „Die Krankheit, sonst bekommen sie die Pupillen größer ... Ich muß immer das Bett absuchen nach Dreieck und Viereck . . beginnender Irreinn, so heilt man ihn aus . . " Ref. dürfe sie nicht anblicken, denn ihr Anblick mache die Hypnose.

3. VI. Die Leute leiden unter dem hypnotischen Blick von ihr. „Ich werde direkt ein willenloses Werk. Sie brauche umzuschauen, wie sich alle mir zuwenden, denn im Blick liegt es, denn ein milder Blick trifft sich sofort. “ Spricht fortwährend, dabei eine dämmerige Heiterkeit ... Reagiert nur wenig auf Fragen.

Auf Drängen der Verwandten in die Landesirrenanstalt.

Die hier nicht wiedergegebenen ausführlichen Krankengeschichten 1903, 1904, 1905, die der Manie vorausgehende Depression, welche im Theresienschlößl genau beobachtet wurde, beweisen mit Sicherheit, daß eine zirkuläre Psychose vorliegt. Die Manie dieser Patientin weist eine Reihe eigenartiger Züge auf. Sie wird von Anfang bis zu Ende beherrscht von der Wahnidee, sie werde von Dr. L. geliebt, er wolle sie heiraten, sie fühlt sich von ihm beeinflußt. Sie hat dabei sexuelle Empfindungen. Diese Sexualempfindungen können aber auch (19. V.) durch eine ,Schwester" ausgelöst werden. Sie wird aber auch durch zufällig vorübergehende Personen beeinflußt. Wir haben das Recht zu vermuten, daß sie die sexuelle Abstinenz nur schwer ertrug, ein stereotyper Traum schon seit 1903 war der Traum von der Brautnacht. Hier bringt also die Manie die teilweise Erfüllung. Aber das Erleiden der sexuellen Erregung gibt ihr auch magische Kräfte. Sie versucht durch zauberische Gesten ihre Mitpatientinnen zu beeinflussen, und sie empfindet Bewegungen der Mitpatientinnen als ihr Werk. Dabei wird sie aber in der stärksten Weise durch Bewegungen anderer angeregt. Hat sie die Bewegung nachgemacht, so erscheint ihr dann die anregende Bewegung als ihr Werk (1. VI.). Als der Ref. in ihrer Gegenwart ein Glas Wasser trinkt, empfindet sie das als Aufforderung, das gleiche zu tun. Hypnotisieren und Hypnotisiertwerden sind für sie offenkundige Sexualakte, wie z. B. die Onanieszene vom 1. VI. eindeutig beweist. In außerordentlich klarer Weise tritt in dieser Psychose hervor, daß für die Patientin Tun und Erleiden im Grunde das- 
selbe sind. Sie fühlt sich durch alle und alles beeinflußt und übt selbst eine magische Wirksamkeit aus. Wirksamkeit ist aber Kraft des Wollens und ist mit sexueller Triebkraft für die Patientin identisch $^{1}$ ). Das ist aber die Anschauungsweise, welche wir gewohnt sind, bei der Schizophrenie anzutreffen. Ich weiß nicht, ob ohne Kenntnis der Vorgeschichte auf der Höhe der Erkrankung die Diagnose der Schizophrenie hätte vermieden werden können. Jedenfalls muß die grundsätzliche Gleichheit des seelischen Ablaufs und die Gestaltung des Erlebnisses betont werden. Die Hyperprosexie, die bis zur Inkohärenz gehende Ideenflucht, den Bewegungsreichtum kann man auch in schizophrenen Zuständen finden, wie z. B. die eingangs mitgeteilte Bobachtung Paula Skr. beweist. Jedenfalls tritt hier in der Manie eine wahnhafte Wunscherfüllung hervor, wobei diese Wunscherfüllung die Züge primitiven Denkens zeigt. Die Wunscherfüllung ist keine völlige. In diesem Zusammenhang sei vermerkt, daß die manische Phase eingeleitet wird von einem Traume (oder einer Phantasie), welche Symbolwert hat. Ein wildes Pferd - es ist nach dem Ausspruch der Patientin der erwünschte Geliebte Dr. L. - verfolgt sie. Die Beziehungen wzischen dem Sexualproblem und der Psychose sind keine sehr eindeutigen. Immerhin sei vermerkt, daß die erste Depression der Neunjährigen sich anschlo $B$ an die Aufwicklung der Frage der Sexualität in der Beichte. Ich bin geneigt, diese Angabe der Patientin als richtig anzunehmen, da sie völlig spontan erfolgte und derartige „Einfälle" der Sache nach das Wesentliche zu bringen pflegen. Eine Reihe von Fragen läßt diese Beobachtung unbeantwortet. Sie klärt die frühe Kindheitsgeschichte nicht auf. Das Verhältnis zu Vater und Mutter bleibt ungeklärt.

Die Ähnlichkeit des Falles 8 und 9 ist in den psychologischen Grundzügen eine außerordentliche, in beiden werden in der manischen Phase nach Art eines Wunschdelirs Wunscherfüllungen erlebt. Wunscherfüllungserlebnisse und manische Vielgeschäftigkeit mischen sich. Ich bin auch hier geneigt, dem Wunscherfüllungswahn eine dynamische Bedeutung für die Produktion des ",manischen Fluidums" zuzuschreiben. Selbstverständlich beschuldige ich nicht einen bestimmten Komplex, daß der die Manie ,hervorgerufen habe“. Derartige plumpe Gedankengänge liegen mir ferne.

Fall 10. Berta Sp., 47 Jahre alt. Klosterschwester. In der Klinik vom 29. II. 1920 bis 13. IV. 1920.

War wegen manisch-depressiven Irreseins bereits zweimal in Anstaltspflege gewesen, und zwar vom 30. September 1909 bis 23. XII. 1909 in Salzburg wegen Manie und vom 25. Februar bis 20. April 1914 ebendort wiederum wegen Manie.

1) Vgl. zu diesen Dingen: Über Halluzinationen. Diese Zeitschr. 53. 169. 1920. 
Leichtere Schübe (Depressionen) verliefen in häuslicher Pflege. In der Familic keine Geisteskrankheiten. Die Pat. leidet seit einem Jahr an Kehlkopftuberkulose. Ftwa 4 Wochen vor der Aufnahme begann die Pat. erregt zu werden, anscheinend im Anschluß an die Mitteilung, daß ihr Kehlkopfleiden hoffnungslos sei. Sie schlief nachts nicht, jodelte, sang viel, war ausgesprochen ideenflüchtig.

In der Klinik bestand Ideenflucht bei heiterer Gemütsstimmung. Die Pat. schrieb und redete sehr viel. Die Ideenflucht war nicht so hochgradig, daß sie nicht, wenn auch mit vielen Abirrungen ein Thema erledigen konnte. Zeitweise reizbar. Die Pat. gab uber ihr Leben sehr genaue Auskunft. Alle diese Auskünfte und Berichte sind in dem Nachfolgenden zusammengezogen. Der Vergleich mit den früheren ausführlichen Krankengeschichten ergab manches Bemerkenswerte, das ihrem Berichte eingefügt wird.

Sie erzählt: Sie war ein sehr lebhaftes Kind. In ihrer frühesten Jugend ereignete sich folgende Geschichte: ,Ich war 3 Jahre alt, es war im Winter ein schöner, aber kalter Tag. Papa und Mama waren zu Hause, die älteren Geschwister in der Schule; ich kam von einem Spaziergang zurick, Papa und Mama saßen beim Tisch, als ich eintrat. Ich begrüßte sie durch ein zärtliches Busserl, denn ich war nämlich von jeher ein kleine Schmeichelkatze. Da fragte Mama die Kinderfrau: Hat sie schon Hoserln gewechselt? Die Kinderfrau antwortete mit nein, und Mama sagte, sie werde das selbst machen. Mama stellte mich auf den Tisch und zieht mir das rote Flanellhöschen aus und das andere Höschen an. Bei dieser Manipulation wurde das Hemdehen verschoben und der Popo der Kleinen sichtbar. Mama ruft aus, hat das Kind aber ein herziges Popoderl und drückt einen Kuß darauf. Papa (bei den Benediktinern in Kremsmünster erzogen) antwortete: Mama gib acht, du könntest dem Kind eine Versuchung machen. Aber Mama meinte lachend: Aber Papa, ich bitte dich, sei doch nicht so überspannt, wie soll denn ein Kind, das noch nicht einmal sprechen kann, fähig sein zu sündigen, schau' nur, wie es mich anschaut, das Patscherl, grad, als ob es sagen wollte: Ist's wahr, also ein schönes Popoderl habe ich. Ich dachte mir damals wirklich, so das wußte ich ja gar nicht, daß ich ein schönes Popoderl habe, schad, da $B$ es mir direkt angewachsen ist, so daß ich es nicht sehen kann. Meine Eitelkeit war sehr befriedigt. Bert1, freue dich, du hast ein herziges Popoderl, das war mein einziger Gedanke. Als ich im Betterl lag, fiel mir wieder mein herziges Popoderl ein; wenn ich es nur sehen konnte! Dieser Gedanke verläßt mich nimmer. Einige Tage darauf trifft es sich, daß ich mich zufällig allein in einem Zimmer befinde, wo ein großer, bis zum Boden reichender Toilettespiegel steht. Hallo, jetzt oder nimmer kann mein Wunsch in Erfüllung gehen. Also rasch zur Tat. Vor allem die Türe geschlossen - o weh, ich reiche ja nicht hinauf, doch da kann man sich ja helfen. Ich trage einen Sessel zur Tür, steige hinauf und schließe sie. Jetzt schnell zum Spiegel. Als ich in den Spiegel schaute und mein Popoderl heraussah, erschrak ich furchtbar und glaubte, Teufel zu sehen; ich bekam Fieber über meine böse Tat und wurde krank." Später verga $B$ sie die ganze Geschichte wieder. Bei der ersten Beichte fiel ihr wie ein Blitz ein, daß sie als kleines Kind eine Todsünde begangen habe, indem sie sich unanständig angeschaut habe $\left.{ }^{1}\right)$. Auch den Hintern ihres Bruders sah sie einmal. Mit 7 Jahren spielte sie mit einem kleinen Mädchen Doktor und Kranksein. Das Mädchen verlangte, daß die Pat. ihr ein Rohr in den Popo steckte, Pat. wollte nicht, weil das unanständig sei, dann gingen sie aber doch auf den Boden und versteckten sich, hier spielten sie abwechselnd mit einem Strohhalm. Pat. beichtete dann, daß sic unanständig gespielt habe. Mit ungefähr 7 Jahren bemerkte sie den Unterschied

1) Schon während ihrer ersten Erkrankung erzählte die Pat. die gleiche Geschichte. Sie fürchtete, nach der Beichte, unkeusch gewesen zu sein und als zweite Magdalena in die Hölle zu kommen. 
zwischen männlichem und weiblichem Geschlecht, sie bemerkte, wie das Glied bei gleichaltrigen Gespielen herausschaute. Bis zu ihrem vierten Lebensjahre war sie das glücklichste Kind, dann starb ihr Vater an ihrem Geburtstag, und von diesem Tag an war Pat. sehr unglücklich. Es waren 7 Geschwister unversorgt zurückgeblieben. Sie wurde dann auf Drängen einer vermögenden Tante zu dieser ins Haus gegeben, wo zwei Knaben von 8 und 6 Jahren waren. Pat. bezeichnet diese Tante als abscheulich. Nun erzählt sie im Detail die Erlebnisse ihrer frühesten Jugend, wie die Tante sie schalt, weil sie undankbar sei. Sie erinnert sich an Gesellschaften, wo viele Offiziere anwesend waren. Sie bekam viele schöne Sachen, sie liebkoste die Offiziere, setzte sich diesen auf den Schoß und nannte sie Papa. Sie wollte nicht mit ihrem 8 jähr. Vetter spielen. Wenn sie aufs Topferl ging, mußte sich die Kinderfrau vor sie stellen und die Kleider ausbreiten, damit die Buberln sie nicht sehen. Eines Tages war die Kinderfrau nicht da, und sie mußte allein aufs Topferl gehen. Da sagte ihr kleiner Vetter, warum sie nicht stehend Wiwi macht, er werde sie das lehren, er tat das, und die Pat. war sehr stolz, ohne ihre Rockerln naß zu machen, stehend. Wiwi machen zu können. (Die Pat. erzählte diese Geschichte sehr drollig und im Ton der Kinderstube.) Am nächsten Tage verklagte sie der kleine Vetter bei der Tante, daß sie ihm ,alles gezeigt" hätte. Die Pat. wurde streng bestraft und mußte das Haus der Tante verlassen, weil sie ein ganz verdorbenes Kind sei. Die Pat. glaubte, daß sie damals keine Sünde begangen habe, und klagte sich nur der Eitelkeit an.

Mit 10 Jahren menstruierte die Pat. zum erstenmal und war neugierig, woher das Blut käme, sie hatte dann entsetzliche Skrupeln, daß sie sich aus Neugierde unanständig berührt habe, und verheimlichte dies auch bei der Beichte.

Die Pat. kam mit 9 Jahren ins Kloster und blieb dort bis zu ihrem 17. Jahr. Dann kam sie nach Hause zu ihrer Mutter, und diese bat sie, ihr Geld verdienen zu helfen. Sie kam dann mit 18 Jahren auf ein Gut nach Ungarn. Sie war so unerfahren und hatte keine Ahnung, wie man sich Herren gegenüber benimmt, da sie noch nie mit einem zusammen war, und im Kloster wurde ihr nicht gesagt, was man tun dürfe und was nicht. (Später im Jahre 1909, als die Pat. nach Salzburg in die Landesirrenanstalt kam, befragte sie den Direktor Regierungsrat Schweighofer, wie man sich Herren gegenüber benehme.) Sie wollte auch, als sie aus dem Kloster kam, auf keinen Ball gehen, weil man dort Todsünden begehe. Auf das Gut nach Ungarn durfte sie nur gehen, weil keine Herren dort waren. Die erste Zeit ging es ihr sehr gut, und dann kam plötzlich der Vater ihrer Zöglinge, ein Rittmeister, zu Besuch. Die Kinderfrau warnte sie und sagte, der Herr Rittmeister suche eine Maitresse, sie solle in der Nacht ihre Türe gut zusperren. Die Pat. verstand den Ausdruck nicht, auch die Warnung nicht, doch fühlte sie instinktiv, daß sie in einer Gefahr schwebe. Der Rittmeister war sehr freundlich und beschäftigte sich tagsüber sehr viel mit ihr, worüber sie sehr verlegen war, fortwährend errötete und sich sehr ungeschickt benahm. Abends, als sie schlafen ging, gedachte sie der Warnung und sperrte ihre Türe zu. Als sie schon im Bette lag, klopfte es; sie öffnete erst längere Zeit nicht, aber auf sein flehentliches Bitten und seine Beteuerungen vertraute sie ihm und machte die Türe auf. Der Rittmeister stürzte herein, sie huschte in ihr Bett, und er setzte sich zu ihr, da begann er sie plötzlich zu küssen und zu berühren. Sie erschrak furchtbar und wehrte ihn mit allen Kräften ab. Als er ihre Schenkeln berührte, zog sie ein Muttergottesbild hervor und stieß ihn mit allen Kräften zurück. Endlich verließ er sie. Sie war sehr unglücklich, glaubte, ihre Unschuld verloren zu haben und eine Todsünde begangen zu haben. Sie schrieb sofort alles ihrer Mutter und mußte sofort nach Hause zurückkehren. (Die Pat. war überhaupt sehr unerfahren, so glaubte sie z. B. auch, daß die Berührung einer Krankenwärterin eine Unkeuschheit sei.) 
Mit 24 Jahren ging sie wieder ins Kloster und wurde Nonne. Sie unterrichtete die Zöglinge und war sehr fromm.

Im Jahre 1909 hatte die Pat. den ersten Ausbruch ihrer Krankheit. Es war in der Zeit der Exerzitien. Die Pat. hatte schon 14 Tage vorher nichts gegesen, um einen reinen Kopf zu haben, und war daher sehr erschöpft. Um diese Zeit hatte sie die erste Halluzination, an deren Wirklichkeit sie übrigens auch jetzt festhält. Sie lag im Bett, plötzlich öffnete sich die Türe, und der Stifter ihres Ordens, der heilige Franz von Sales, trat ein. (Sie beschreibt genau seinen Anzug und seine Bewegungen.) Die Pat. zitterte vor Vergnügen, daß sie einer himmlischen Erscheinung gewürdigt werde. Der Heilige nahm ihr die Arme vom Kopf herunter und sagte, daß das ungesund sei, dann lockerte er ihr die Röcke und sagte, es sei nicht gesund, so enge Röcke zu tragen. Die Pat. war sehr enttäuscht, daß der Heilige nur über ihre Gesundheit sprach. Während dieser Erscheinung hielt sich die Pat. für ein ungefähr 9 jähriges Kind.

Einige Tage später hatte Pat. folgenden Traum: Es war ein großes Königreich, dort gab es einen König, der von seinen Untertanen sehr geliebt und verehrt wurde. In dem Lande gab es nur glückliche Leute und, sooft der König seine Untertanen fragte, ob er ihnen eine Freude machen könne, sagten sie, sie hätten alles. Das wurde dem König langweilig, denn er wollte immer Gutes tun. Eines Tages faßte er einen Entschluß. Ich muß Gutes tun, darum werde ich meine Leute verlassen und irgendwo hingehen, wo es Bedürftige gibt. Da sagten alle Untertanen, sie gingen auch mit, und es bewegte sich ein langer Zug dorthin, wo es Bedürftige gab, dieser Ort hieß Erde. Dort gab es eine große Schmutzlacke, in der sich etwas bewegte wie ein spannlanger, schwarzer Wurm. Die ganze Prozession wandte sich mit Ekel ab, nur der König sah hin und, wie er in die Nähe kam mit seinem prachtvollen Gewand und seiner Krone, kniete er nieder, hob das Würmlein anf, und es war ein kleines Kind, das abscheulich war, schmuztig, mit Wunden bedeckt und stinkend. Der ganze Zug blieb stehen und wandte sich mit Abscheu ab, der König aber drückte es an sein Herz. Das Kind war selig in seinen Armen, dem König aber tat es weh, daß seine Leute das Kind verachteten, und er steckte es unter seinen Mantel. Da war in seiner Brust ein Loch von einem Lanzenstich, das Kind fiel hinein, es war etwa so groß wie eine Gliederpuppe und blieb bis zum Kopf drin stecken. In der Wunde war Blut und Wasser, es war wie ein angenehmes Bad; darin kräftigte sich das Kind und verlor seine Wunden. Dann griff der König hinein und zog es heraus, da war es so entzückend, daß man es nicht mehr verstecken mußte. Die Königin streckte die Arme verlangend nach ihm aus, und der König gab es ihr einen Augenblick. Der König griff wieder verlangend nach dem Kind und wollte es der Königin nicht lassen, dann ging der ganze Zug weiter. Das kleine Kind war die Pat. selbst, der König war Christus der Erlöser, die zweite göttliche Person der Welt, die Königin war Maria die Jungfrau, seine Mutter. Dieser Traum war anfangs September 1909 in der Zeit der 10 tägigen Exerzitien. Die Pat. schlief damals nicht und hatte in der Nacht Gedanken, sie wußte nicht, ob sie wachte oder träumte. Während der Exerzitien wurde gebetet und betrachtet.

Die fünf Betrachtungen waren:

1. Wozu bin ich auf der Welt?

2. Vom Sündenfall der Menschen.

3. Von der Bosheit der Sünde und ihren schrecklichen Folgen und ähnliche Betrachtungen über Tod, Hölle und Ewigkeit. Vor den Exerzitien war die Pat. sehr erschöpft, nachher aber sehr gesund, so „,daß sie auf die höchsten Berge hätte steigen können". Auch konnte sie in den höchsten Tönen singen und fühlte sich sehr glücklich. Sie war schon vorher immer lustig gewesen und wurde der lustige Christus genannt. 
Einige Tage später hatte sie wieder eine Erscheinung. Das Bild von Führich, das über ihrem Bette hing, wurde lebendig. Das Jesuskind lag auf ihrem Bett, Josef und Maria waren anwesend. Die Pat. war so entzückt, daß sie nur schauen konnte. Auf einmal sagte der Schutzengel, knie nieder und bete an. Sie kniete im Bett nieder und betete einen Rosenkranz. Nach einer Viertelstunde konnte sie sich vor Wonne nicht mehr halten, und sie begann zu singen. Dann war sie wie in Ekstase bis zum Morgen. Sie spürte keine Müdigkeit und ging zum Chor hinunter. Sie glaubte damals nicht, daß sie krank sei, wurde aber von ihrer Umgebung dafür gehalten. Sie wurde auch von der Oberin bestraft, weil sie nicht einfach und natürlich sei. In den ersten Tagen nach ihren Erscheinungen verstand sie alles, was sie las, besser als je und drang tief in den Geist ein, dann konnte sie nichts mehr machen, sie merkte sich gar nichts und war ganz von Gott eingenommen. „Das ist, als wenn man verliebt ist." Sie konnte nur an Gott denken, sie war von einer Wonne erfüllt, die im ganzen Körper war, und zitterte fortwährend. Geschlechtliche Empfindungen hatte sie keine, ,da sie solche Gedanken mit Abscheu von sich wies". Sie hatte dann wieder eine Erscheinung: Auf dem Sessel neben ihrem Bett saß eine Gestalt, von der sie wußte, daß es der göttliche Heiland sei, und er sagte, er werde sie singen lehren. Er fing mit einer prachtvollen Tenorstimme zu singen an: „Ich lebe doch nicht ich, denn Jesus lebt in mir, ich singe doch nicht ich, denn Jesus singt in mir." Dann hörte sie eine herrliche Melodie zwei- und dreistimmig ron wunderbaren Akkorden begleitet. Sie mußte dann später dieses Lied immer wieder singen. Sie sang es den Klosterschwestern immer wieder vor, bis es ihr verboten wurde. Da begann sie es in allen Sprachen zu schreiben und in Noten zu setzen. Von diesem Moment an war Jesus immer bei ihr, nur wenn sie im Bette lag, sa B er neben ihr. Sie empfand in dieser Zeit eine unbeschreibliche Seligkeit. Sie wurde von der Oberin barsch abgefertigt, sie brach in Weinen aus und fühlte sich als ein Gemisch von Kraft und Schwäche. Sie sagte, sie könne nicht mehr weiter und wurde ins Krankenzimmer gebracht. Auf eine Frage sagte sie, sie sei sehr glücklich und liege im Herzen Jesu, so wie die heilige Mutter Gottes in ihrer Wiege. Sie empfand ein großes Glücksgefühl und wollte immer singen. Sie fühlte sich wie ein Betrunkener. Sie umarmte die Klosterschwestern heftig und brach sogar das kanonische Stillschweigen durch ihr Singen; sie benahm sich überhaupt wie eine Verrückte. Sie wurde als krank behandelt und sang und dichtete den ganzen Tag. Der Arzt wurde zu ihr gerufen; sie nannte ihn Papa und wollte ihm durchaus ein Busserl geben. (Sie führt das darauf zurück, daß er im selben Kloster erzogen wurde wie ihr Vater.) Der Arzt sprach von ekstatischen Zuständen; sie freute sich, daß sie wirklich eine Ekstase gehabt hatte, sie wollte nichts mehr essen und nur mehr von der heiligen Kommunion leben. Auf einmal war sie in der Idee, sie sei ein kleines Kind. (Infolge eines Theaterstückes, in dem sie kurze Zeit vorher die Rolle eines kleinen Kindes gespielt.) Es fiel ihr das Wort des Heilands ein: So ihr nicht werdet wie die Kindlein, werdet ihr nicht in den Himmel eingehn. Da sie ohnedies ein kindliches Gemüt hatte, fiel es ihr nicht schwer, es zu sein. Dann hielt sie sich plötzlich für das Jesukindlein, sie verlangte, daß man ihr Löckchen mache, und wollte in eine Krippe gelegt werden. Da wurde sie unwohl und fragte eine Schwester, ,ob die Buberln auch unwohl werden ?" Sie war dann nicht mehr sicher, ob sie das Jesukindlein sei; sie kannte sich nicht aus, ob sie ein Buberl oder ein Mäderl sei. Den Arzt hielt sie für ihren Papa, sie wurde immer lustiger und hatte ein großes Liebesbedürfnis; sie wollte dem Arzt durchaus einen Kuß geben, der ihn unter dem Vorwand, sie sei nicht brav genug, ablehnte. Da beschloß sie, sehr brav zu sein, tat alles, was man von ihr verlangte, und überwand sich mehrmals im Tag. Als der Arzt trotzdem sagte, sie sei nicht brav genug, brach sie in Weinen aus und wollte wenigstens den Papasegen haben. Einmal erzählte sie einer Schwester fol- 
gende Geschichte: Ein Onkel von ihr war 4 Jahre alt, als er einmal von seiner Mutter ausgezogen wurde, eine alte Dame, die dabei war, berührte das Kind am Popo, da wandte er sich um und rief: Weich von mir, du Unkeusche. Die Schwester war entsetzt über diese unkeusche Geschichte und hielt der Pat. vor, daß man das Wort Popo nicht aussprechen dürfe; da wurde die Pat. unwillig und wiederholte das Wort fünfmal. Sie wurde bestraft und eingesperrt. 3 Wochen lang hielt sie sich für ein Kind, das in den Himmel fährt mit einem goldenen Wagen und weißen Renntieren. Dann hielt sie sich plötzlich für eine kleine Nachtigall. Der Heiland war bei ihr und sie saß bald auf seinem Kopfe, bald auf seiner Schulter. Sie nannte sich die kleine Nachtigall des Herzens Jesu und war sehr böse, wenn ihr das jemand ausreden wollte.

Beim Baden wollte sie kein Hemd anziehen, sie sträubte sich aufs heftigste und sagte, Adam und Eva hatten auch keine Hemden, nur böse Menschen brauchen Hemden. Der Heiland war oft bei ihr und erzählte ihr die Geschichte vom verlorenen Sohn und das Gedicht vom Erlkönig so ruhrend, daß ihr ganz heiß ums Herz wurde.

Die Pat. kam dann in die Landesirrenanstalt nach Salzburg. Erst hielt sie den Direktor für den Heiland und den König aus der Parabel, auch duzte sie alle Ärzte. Sie war tief erschüttert, daß man sie für eine Närrin hielt, während sie glaubte, eine Heilige zu sein. Sie schämte sich sehr und war tief deprimiert. Sie hatte geglaubt, die Welt bekehren zu müssen, und zwar durch ihren Gesang. Sie wollte im Kloster hinter einem Gitter Konzerte geben und geistliche Lieder singen; auch Liebeslieder wollte sie singen, sie bezog sie aber alle auf den Heiland. Sie wollte die Welt durch ihren lieblichen Gesang rühren. Sie bezeichnet diesen Gedanken als die Gesundidee ihrer Krankheit. In der Anstalt in Salzburg war sie sehr heiter, erst verweigerte sie im Examen die Antwort, dann aber hörte sie plötzlich die Stimme des Heilands, der sagte: Kind, gib Antwort wie in der Beichte, ich werde alles zum Besten lenken.

Zur Ergänzung aus der Krankengeschichte der Landesheilanstalt: Nach dem Bericht einer Klostersehwester war die Pat. bis Anfang September 1909 völlig unauffällig, kam als Musiklehrerin ihren Verpflichtungen nach, war bei den Schülerinnen besonders beliebt, war musikalisch begabt. Seit zirka 5 Jahren litt sie an Verdauungsstörungen. Im letzten Schuljahr, besonders während der Ferien habe sie sich überanstrengt, viel Musik getrieben und komponiert. Nach den Exerzitien (19. VIII. bis 9. IX.) sei sie besonders auffällig gewesen, habe nächtelang nicht geschlafen, stets gesungen und viel gesprochen. Sie sagte, der liebe Gott sage ihr alles, was sie tun müsse. Gegen die anderen Schwestern war sie besonders freundlich, umarmte sie oft und versicherte, Gott sei in ihr, und sie sei selig, da sie mit göttlichen Personen in Verbindung stehe. - In der Anstalt erwies sie sich als logorrhoisch, ideenflüchtig. Sie äußerte die gleichen Ideen, die oben vermerkt sind. Die 5 Jahre vor dem Ausbruch der Erkrankung habe sie sich wiederholt Gedanken wegen ihrer Jugendsünden gemacht und sei deswegen niedergeschlagen gewesen. - Im 10. Lebensjahr sei sie im Anschluß an mehrere Todesfälle von Verwandten verstimmt gewesen, danach sei sie hochgradig ängstlich gewesen, habe Gespenster gesehen, die mit langen und mageren Fingern nach ihr griffen.

Nach 3 Monaten wurde sie entlassen und kam wieder ins Kloster, sie war sehr niedergeschlagen und traurig. Das Essen war ihr zum Ekel und sie hatte fortwährend Sehnsucht, Klavier zu spiclen und zu singen, das war ihr aber verboten. Sie blieb 5 Jahre im Kloster. Dann überanstrengte sie sich bei der Pflege kranker Kinder. Damals wurde sie tief erschüttert durch die Nachricht, daß ihre Schwägerin im Anschluß an eine Entbindung in einem Verwirrtheitszustand sei. Zu dieser Zeit hatte sie auch einen schmerzenden Finger, so daß sie längere Zeit schlaflos 
war. Sie hatte Kopfschmerzen und war sehr reizbar. Nach den Angaben einer Mitschwester weinte sie viel, sang, schrieb viel, hatte Rededrang. War labil in der Stimmung. Dann wurde sie lustig, sang, spielte in der Nacht. wollte Geld verdienen, Wohltätigkeitsvorstellungen geben, wollte dadurch 3 Millionen verdienen, wollte in Salzburg ein Haus bauen, in dem Knaben und Mädchen von Geburt an erzogen werden. Dachte, Pater K. sei ihr Vater, sie selbst sei heilig, sie wolle mit Pater K. in die Wüste reisen, als Einsiedlerin leben; sie sei die Nachtigall oder der Aar vom göttlichen Herzen Jesu, könne in die Herzen Pfeile schießen. Pater K. könne sie so klein machen, daß er sie wie ein Federmesser in die Tasche stecken könne. Sie wollte für das neue Haus Harmonium und Klavier kaufen. Sie wurde unter dem Vorwand, ihren Bruder zu besuchen, nach Salzburg in eine Heilanstalt gebracht (1914). Ủber diese Täuschung war sie sehr aufgeregt. Nach 1 Monat wurde sie wieder entlassen. In der Anstalt war die Stimmung bald heiter, bald depressiv, aber immer ideenflüchtig, abschweifend. Aß nicht, hatte Befehl des Heilands hierzu. Bezeichnet sich als Nachtigall des Jesu, meist selig, heiter. Sie wollte in der Wüste büßen, sie sah Jesus Christus als kleines Kind schweben. Die Pat. kam dann noch zweimal wegen Kopfschmerz, Schlaflosigkeit und Reizbarkeit in ein Erholungsheim.

Anfangs Februar 1920 wurde Pat. wieder schlaflos und bekam Kopfsehmerzen. Sie hatte auch ein Halsleiden und regte sich freudig darüber auf, daß ihr Leiden für Tuberkulose erklärt wurde, weil sie dann bald in den Himmel komme. Sie hatte solche Kopfschmerzen, daß sie die Ordenstracht nicht ertragen konnte. Sie war sehr heiter und fröhlich in dem Gedanken, bald in den Himmel zu kommen. Einige Tage vor ihrer Einlieferung in die psychiatrische Klinik erzürnte sie sich sehr über ejne Schwester, die sich darüber aufhielt, daß die Pat. keine Ordenstracht trage, dann regte sie sich sehr darüber auf, weil ein Auftrag an ihre Schwester nicht ausgeführt wurde. Sie geriet deshalb $\mathrm{mi}^{+}$einer Klosterschwester in heftigen Streit und beschimpfte diese. Die Oberin wollte sie auf die psychiatrische Klinik bringen lassen, Pat. sträubte sich aber heftig. Auf Zureden ihres Beichtvaters fugte sie sich schließlich, obwohl sie überzeugt war, daß ihr Unrecht geschehe.

Die Pat. ist sehr gerührt, denkt viel an ihren Tod und kränkt sich, daß sie die Sohwestern im Kloster nicht mehr sehen werde.

Am 4. III. 1920 hatte Pat. folgenden Traum (sie weiß nicht, ob es ein Traum oder eine Erscheinung war): Sie lag wie in einer tiefen Narkose und sah sich in einem prachtvollen Palast, wie zur Zeit der Römer; sie ging über viele Stufen, so wie man z. B. ins Theater oder in die Oper geht. Es war eine Art Theater, und sie nahm ihren Platz ein. Das Orchester setzte ein, und es begann ein Balett, es kamen 16 reizende junge Mädchen herein, die alle so aussahen wie eine Mitpatientin und in prächtigsten, orientalischen Farben gekleidet waren. Die Mädchen begannen einen Tanz nach einer lieblichen Weise, dann verschwamm das ganze Bild vor den Augen der Pat., und sie wurde von einer Mitpatientin aufgeweckt.

Die Pat, zeigte in der Zeit, wo sie die vorstehenden Angaben machte, ein ausgesprochen manisches Wesen. Heiter, ideenflüchtig, abschweifend. Sie schreibt, komponiert. Dabei sind unter den Gedichten solche, die sinnlich, derb-mundartlich sind. Meist preist sie aber die Seligkeit der Frömmigkeit. Thre Stimmung ist manisch-lustig, mit Neigung zu Scherzen, sie ist freundlich, zutunlich. Ein besonderes Gepräge enthält diese Manie dadurch, daß eine rührende Seligkeit die Pat. häufig überkommt. Zeitweise leuchtet eine gewisse Trauer und Angst vor dem Tode durch. So spielt sie um den 20. III. einige Tage viel mit einem Bleistiftstückchen, das sie ins Wasser wirft und das dann dort sich senkrecht aufstellt. Sie schließt daraus, daß der Tod zu ihr kommen würde. Das sei der Tod. Sie hörte auch in der Nacht klopfen und glaubte, es sei der Tod. Sie gibt den Tod (das Stück- 
chen Bleistift) in eine Schale, wenn sie ihn nicht haben will. Dann wieder drückt sie diesen ,Tod" an die Brust. Mit der zunehmenden körperlichen Schwächung (sie fiebert hoch) treten kurzdauernde Depressionen stärker hervor. Immer aber betont sie die Seligkeit der göttlichen Liebe. Dann schlägt stets die Heiterkeit und Lustigkeit durch. Sie ist unaufhörlich beschäftigt mit dem Herausputzen der Zelle, mit Schreiben u. dgl. m. Am 28. III. erzählt sie, sie sei im Himmel gewesen und könne nicht beschreiben, wie herrlich es dort sei. Am 13. IV. fast moribund in das Kloster zurück. Sie war schon ungefähr eine Woche vorher ruhiger geworden. Doch blieb die heitere Gemütsstimmung vorherrschend.

Die Beobachtung ist in vieler Hinsicht bemerkenswert. Die früheste Erinnerung der Patientin, welche sie in das Alter von $1 \frac{1}{2}$ Jahren verlegt, ist Stolz auf ihren schönen Popo und Entsetzen über ihren Körperteil, als sie ihn im Spiegel betrachtet. Die Patientin rechnet sich diese Handlung als Unkeuschheit an, und ihre erste Depression schließt im Alter von acht Jahren an die Erinnerung dieses Erlebnisses an. Mag auch der Zeitpunkt des Erlebens von der Patientin nicht genau wiedergegeben sein, mag es entstellt sein, das Wesentliche dürfte richtig erinnert sein. Denn Anales spielt bei der Patientin in der Kindheit noch einmal eine Rolle, und in der Psychose des Jahres 1914 taucht zugehöriges Material auf. Man darf also vermuten, daß dieses frühe Erlebnis nicht belanglos war für die weitere Entwicklung des Seelenlebens. Denn aus ähnlichen Zweifeln, Skrupeln, Selbstvorwürfen erhebt sich ja ihr erster manischer Schub des Jahres 1914. Er beginnt halluzinatorisch. Zuerst ist es der Gründer des Ordens, dann aber Jesus selbst. Wenn man auch in jener Szene, wo der König das spannenlange Würmchen aufnimmt und in seinem Körper reinigt, die Nachwirkung schwärmerisch phantastischer Gebete, die Seitenwunde Christi betreffend, nicht verkennen darf, so muß andernteils doch unterstrichen werden, daß eine durchsichtige Symbolik vorliegt. Die Patientin als Kindlein spielt die Rolle des Penis. Christus ist in eine weibliche Rolle gedrängt. Die Geschlechtsverwandlung der nachfolgenden Strecke der Erkrankung fügt sich zwanglos ein. Anal-Homosexuelles ist also einesteils Inhalt der Depression, andernteils erscheinen diese Triebregungen, wenn auch in symbolischer Verkleidung in dieser ersten Psychose erfüllt. Im übrigen ist die ekstatische Seligkeit mit Sexualität durchtränkt. Die Patientin ist eins mit Jesus. Der selige Liebesrausch führt sie in die Kindheit, macht sie zum Buben und sie erhält die Möglichkeit, das Verpönte ungescheut wieder durchzuerleben ... (Erzählung vom Onkel.) Weniger durchsichtig ist die Genese der beiden anderen manischen Phasen. Die des Jahres 1917 knüpft an die Verwirrtheit der Schwägerin nach einer Geburt an und ist erfüllt von Größenideen. Eine Vaterfigur, der Pater K., spielt eine wesentliche Rolle... (der Vater ist für die Patientin überhaupt von großer Bedeutung). Schließlich die dritte Phase in offenbarem Zusammenhang 
mit der Einsicht in die Tödlichkeit ihres Kehlkopfleidens stelit einen großartigen Ưberwindungsversuch dar, durch und mittels des Eros über den Tod Herr zu werden. Daß der Gedanke an den Tod doch immer da ist, bezeigt besonders klar jene kleine Episode, in der sie in einem Holzstückchen ein Symbol des Todes sieht. Diese Manie ist symptomatologisch typisch, nur daß die Unruhe, Lustigkeit und Heiterkeit hier gemengt ist mit Seligkeit. Wohl deshalb, weil die Patientin aus ihrer religiösen Einstellung heraus die Vereinigung mit Jesus sexuell genießend erlebt.

Wiewohl die günstigen Umstände des Falles es ermöglichten, mit der Analyse tief einzudringen, muß doch die Frage aufgeworfen werden, ob denn die Erlebnisse verständlich machen, daß aus ihnen gerade eine Manie erfloß. Diese Frage möchte ich verneinen. Fre ud ${ }^{1}$ ) hat sich bei der Analyse eines Falles von weiblicher Homosexualität die gleiche Antwort gegeben. Die Wirkung der Erlebnisse ist nicht nur durch diese bestimmt, sondern auch durch einen Faktor, der vor den ersten Erlebnissen liegt und schon die Erlebnisse selbst formt. Diesen Faktor darf man als konstitutionellen kennzeichnen. Man muß aber sagen, er wird sich wohl im Erlebnis anzeigen müssen, so daß das wirksame Erlebnis gleichsam als Abbildung dieses Faktors erscheint, und die Konstitution wird sich wohl an verschiedenen Stellen immer wieder im Erlebnis abbilden. Es wäre also denkbar, daß es in Zukunft besser gelingen wird, aus den Jugenderlebnissen die manischdepressiven „Folgen“ abzuleiten. Aber auch dann wären die Jugenderlebnisse nur Zeichen eines Tieferliegenden, doch davon mehr im Schlußwort dieser Arbeit.

Für diese Patientin erfolgte im ersten Schub der Manie wirklich eine Rückkehr zur Kindheit. Ich halte es jedoch nicht für zulässig, wie dies $\mathrm{Abraham}^{2}$ ) tut, die Ideenflucht, die gehobene Stimmung, die Labilität des Erlebens, die Neigung zu Wortspielereien als Regression in die Kindheit aufzufassen. Gewiß, derartiges findet sich gelegentlich im kindlichen Erleben, aber es findet sich auch in der Alltagspsychologie des Erwachsenen, und der Kindergrößenwahn ist wohl auch in wesentlichen Stücken von dem gehobenen Selbstgefühl der Manischen verschieden. Das Prinzip der Regression ist sicherlich grundsätzlich richtig. Es ist sicher richtig, daß bei Erkrankungen phylogenetisch und ontogenetisch frühere Entwicklungsstufen des Erlebens wieder auftauchen. Dieses Prinzip darf jedoch durch allzu weitherzige Anwendung nicht diskreditiert werden.

1) Über die Psychogenese eines Falles von weiblicher Homosexualität. Internationale Zeitschr. f. Psychoanalyse 6, 1. 1920.

2) Ansätze zur psychoanalytischen Erforschung und Behandlung des manischdepressiven Irreseins. Zentralbl. f. Psychoanalyse 1912. 
Fall 11. Marie J., 26 Jahre alt, geboren 1893. In der Klinik vom 25. V. bis 25. X. 1919.

Familienanamnese belanglos. 1905 machte die Pat. eine schwere Hirnerkrankung durch. Kopfschmerzen, Opticusatrophie. 1907 Schwäche der rechten Körperhälfte. Seit 1909 allmähliche Besserung. Die Diagnose schwanke zwischen Tumor (Pseudotumor) cerebri, Hydrocephalus und Encephalitis. Zur Zeit der Aufnahme in der Klinik war noch vorhanden: Opticusatrophie rechts stärker als links. Nur am linken Auge ist Farbenerkennung, Fingerzählen und Projektion möglich. Bauchdeckenreflexe fehlen. Spastische Parese des rechten Beines geringen Grades und geringe Ataxie der linken Extremitäten. Während dieser ganzen Erkrankung war die Pat. heiter-geduldig. Auch später überwog dieser Zug in ihrem Wesen. Sie sang oft plotzlich heraus. Menses seit Beginn der Erkrankung unregelmäßig. Am 3. V. 1919 erkrankte sie mit Bronchitis und hohem Fieber. Seit 21. V. verworren. In der Klinik lärmend, singt, schreit. Dabei ist ihre Orientierung eine gute. „Seit 3 Tagen träume ich von Engeln, herrliche Träume. Engelmann, Zipfelmann, Doktormann, Engel, Bengel. Auch Herr Professor renne an. Rette mich, rette mich." Dann: „Das sind die Nerven, die rennen wie Räder, die Nerven, die zappeln, er rennt, er rennt, er ist schon gleich bei mir. Himmelmann, Schimmelmann. Alle Nerven fort. Herr Doktor, wo bist du? O schau' mich doch an. Ich habe die Kraft von ihm, seine Nerven, die haben die Kraft, er hatte mir die Kraft gegeben. Ich klappre wie ein Klapperstorch. O Klapperstorch, Klapperstorch, Zipfelmann, Herr Professor. O mein alles, ich bitte dich, ich hab' doch keine Ruh'. Ach komm herein, ich hab' kein Bein." Dieser spontane Duktus bezieht sich auf ihren Hausarzt ... Sie ist in heiterer, rosiger Stimmung, sie ist zugänglich, freundlich. Niemals ein Zornaffekt, niemals ein Anflug von Depression. Es ist ein Zustand heiteren Sichselbstgenügens. Am 10. VI „Sie ist gescheiter als ihr alle", sie sei die Kräftigste, sie fühlt sich ganz gesund. Sie faßt die Ärzte immer bei der Hand, klammert sich an sie, ,das sei ein Nervenzieher". Man macht die Menschen so gesund. Die Ärzte seien "schlimm", weil sie ihr die Hand nicht geben wollen ... Sie ist aufmerksam, hört eine Männerstimme. Freudig erregt. „Wann kommt der Mann ..." Stets ist eine infantile Erotik in ihren Gesprächen und Handlungen deutlich. Sie träume oft stets angenehm von göttlichen Personen und von der Familie. Bericht von einigen Träumen. Die Pat. spricht rasch, ist zeitweise etwas erregt, aber immer verklärt, lustig, spricht mit sich, führt ein Theater für sich selber auf, spricht mit imaginären Personen (offenbar keine Halluzinationen), sie ist aber fixierbar, schwärmt dann glückselig, klagt nur gelegentlich über ihr Nervenleiden. Dabei in ständiger Bewegung.

In der Folgezeit wurde die Pat. ruhiger. Die heitere, rosige Stimmung bleibt, auch die folgenden Stilproben entstammen der gleichen Stimmung. Die Pat. überläßt sich beständig kindlich-spielerischen Gedankengängen, etwa den folgenden:

4. IX. „Wie ich anfangs hier war, kam öfters der Doppelpunkt und der Punkt (Wer ist das ?) Mein Bruder und meine Schwägerin. (Haben sie geträumt ?) „,O ja, einmal von einem Glas und in demselben waren Kümmel, zwei Pfefferkerne und ein Knochen, es war ein schöner Traum.“ (Was war in dem Glas?) „Das war vielleicht ich, aber die Augen sind nicht gesund. Die Träume sind aber alle zerflossen."

Pat. wird etwas unwillig und sagt, sie hätte das alles übrigens schon erzählt. (Was sonst noch geträumt?) „Ich träumte einmal von den göttlichen Personen, die um mich waren, und ich war dabei ein kleines Kind, ein kleiner Wurstl." (Ist das ernst zu nehmen?) „Aber ich mach' ja eine Hetz mit den Herren um Gottes willen." 
10. IX. Die Pat. erzählt von ihrer früheren Krankheit, die Ärzte sagten, da sei nichts zu machen, und ihre Augen sind schlecht geworden. Dr. M. habe sie untersucht und ihr gesagt, was es sei. ,Ich bin ja ein kleines Kind gewesen, und wie jch dann ausgegangen bin, habe ich mich vor den Buben geniert." (Pat. erzählt das lachend.) Sie mußte damals schwarze Brillen tragen, ,, aber die Sonne ist ja gerade gut ?" "Ich war schon immer ein krankes Mädel schon von meinem siebenten, achten Jahr an vielleicht, wahrscheinlich ist es ein zurückgebliebenes Leiden (lacht dazu). Schwamm darüber und Schluß, was ist denn das Ganze?" Sie möchte lieber in die Luft springen, als hier sitzen. „Ich bin ja gar nicht diejenige, ich bin immer ganz verdreht, wenn ich die Ärzte sehe, ich war aber mehr oder weniger lustig." (Erzahlen sie uns etwas von ihren Tráumen.) ,Ich war zu Hause, meine Schwester lag im Bett, und die Tante Tilde saß bei ihr, auf einmal war ein Herr da, es war ein Geistlicher, ich habe ihn aber zuerst für einen Arzt gehalten." (Hat er einen so tiefen Eindruck auf sie gemacht?) „Aber das ist ja Unsinn!" (Was geträumt?) Polnisch habe sie erst jetzt gelernt. (Erzählen sie uns von den Träumen.) „Ich habe von einem Glas geträumt, das war so hoch und breit (Pat. zeigt zirka $15 \mathrm{~cm}$ ), da waren Kümmelkerne drinnen in Essig eingelegt, und ein Knochen war auch drinnen und obenauf waren drei Punkte, zwei Pfefferkerne und einer extra, die habe ich den Doppelpunkt und den Punkt genannt, und das waren mein Bruder, die Schwägerin und das Kind." (Aber das ist doch kein unangenehmer Traum.) „Nein.“ (Haben sie von bösen Männern geträumt?) „Nein. (Erzählen sie uns weiter von ihren Träumen.) „Von dem Mann habe ich ihnen doch schon erzählt, der zur Türe gekommen ist, das war am 22. V., ich habe ihn immer hinausgeworfen, es war ein ekelhafter Bettelmann, ich zerdrückte ihn, nein, ich habe mit dem gerauft, und hinausgeschmissen habe ich ihn auch, dann habe ich mit meiner Schwester gestritten und den Bettelmann dann nach Kagran gesetzt, und einmal am Schneeberg, da waren drei Glocken, und jemand hat geläutet, die ganze Geschichte war aber ein Traumbild, und der Esel, der Steinbock und alle die Tiere waren auch immer nur ich." (Was heißt das, der Esel, Steinbock und die anderen Tiere waren immer Sie ?) „Bei den Träumen das war immer ich." (Was war immer ich, das verstehe ich nicht?) „Der Emmerich und alles andere war immer ich.“ (Was heißt das?) „Ich weiß ja nicht, ob ich es immer war, aber der Steinbock das war das harte Bett, Bock habe ich auch gesagt, und die Decken, die auf meinen Füßen lagen, waren das harte Brett.“ (Was war mit dem Steinbock ?) „Jetzt fragt er schon wieder, ein dummes Mädel war ich, ein Gansel und bin vom Gänserich gefangen worden." (Das müssen Sie uns genauer erklären und weshalb Sie hier sind?) „Ich bin nach der Grippe hergekommen, aber das wissen Sie ja so schon alles."

Eine heitere, kindliche Gemütsstimmung bleibt bis zur Entlassung bestehen, doch ist die Pat. völlig ruhig und zugänglich geworden.

Dieser Fall ist trotz der komplizierten ätiologischen Verhältnisse als Manie aufzufassen. Es ist dieser manische Ausbruch Grippefolge ${ }^{1}$ ). Die affektiven und gedanklichen Veränderungen entsprechen denen der Zustandsbilder des manisch-depressiven Irreseins. Symptomatologisch ist die besondere Zartheit der Stimmungen bemerkenswert, es ist Heiterkeit, rosige Seligkeit, leise Erotik. Bestimmte Komplexe konnten nicht nachgewiesen werden, wenn man nicht die Sehnsucht nach Prof. M. so deuten will. Es ist wahrscheinlich, daß die psycho-

1) Hierüber vgl. Kleist, Die Influenzapsychose und die Ätiologie der Infektionskrankheiten. Springer 1920. 
logischen Charaktere dieser Erkrankung zum Teil mitbestimmt sind durch die vorangehende schwere Gehirnerkrankung. Dafür spricht auch, daß die sanfte Heiterkeit nach dem Abklingen des Erregungszustandes noch zurückblieb. Schließlich tragen die symbolischen Spielereien der Kranken einen infantilen Zug. Solcher spielerischer Symbolismus war aber auch im Falle 10 nachweisbar und zeigt sich auch im folgenden Falle. Es ist nur ein Nebenzug des Gesamtbildes und er kann, trotzdem er infantil ist, nicht die Annahme rechtfertigen; Regression zum Infantilen spielten in der Manie eine wesentliche Rolle.

Fall 12. Friedrich P., 51 Jahre alt. In der psychiatr. Klinik vom 2. VIII. bis 29. VIII. 1920.

Der Pat. war zum erstenmal im März 1912 in der Klinik. Seine Frau gab damals an, seit 8 Jahren sei der Pat. im Frühahr immer sonderbar. Bei der ersten Erkrankung mit 35 Jahren sah er die Jungfrau Maria vor sich, er wurde schlaflos, wurde erregt. Bei jeder Erkrankung sei der Pat. erregt, trinke viel, äußere Größenideen, er sei der Sohn eines Grafen, verfüge über Millionen. Er spreche wertloses Zeug, sehe in Personen der Umgebung Verstorbene. 3 Tage vor der Aufnahme (1912) wurde der Pat. schlaflos, sah seine Mutter und Lueger im Glorienschein vor sich und erhielt von ihnen die Weisung, links zu gehen. Er zeigte in der Klinik ausgesprochene Ideenflucht. Heiterer Affekt mit Neigung zu Zornausbrüchen und auch zum Weinen. Auch von einer Reihe weiterer Attacken existieren Krankengeschichten, welche das typische Bild schwerer ideenflüchtiger Manie zeigen. Etwa 8 Tage vor der letzten Aufnahme in die Klinik begann der früher Fleißige und Ordentliche wieder erregt zu werden, trank. In der Klinik ist der Pat. dauernd sehr unruhig. Er redet und schreit sehr viel. Neigung zu Beschimpfungen und Drohungen. Manisch heiter, doch Neigung zu Zornausbrüchen. Gelegentlich auch Weinen, das offenbar nur einem wenig tiefen Affekt entspringt. Typisch schwerc Ideenflucht, Neigung zu Witzeleien, sonderbare Ideen, die spielerisch festgehalten werden, z. B. Nicotin ist Urin. Motorisch sehr erregt, malt mit der Marmelade auf der Wand seiner Zelle. Die ganze Erkrankung wird beherrscht von immer wiederkehrenden Gedanken über seine Abstammung, am 8. VIII. schreibt er den Namen in der verschiedensten Weise und knüpft etymologische Spielereien daran. Am 9. VIII. gibt er auf die Frage, ob er geträumt habe, zur Antwort: „Ich träume von Gott, Heiligen und dem Papst, von Kaiser und Königen ..." „Mein Ziehvater ist Fiaker." Der wirkliche Vater sei Kaiser und königliche Hoheit Franz Joseph, ,das ist bestimmt, weil ich in der nächsten Nähe von Schönbrunn geboren bin", seine Schwester hieße Hohenberg. Er der Pat. heiße Vandenberg, „weil er viel über Berge wandere". Eine Chefin von ihm hatte große Ähnlichkeit mit seiner Mutter. Am 11. VIII. ,Ich bin Gedankenleser und bilde mir heute ein, ich bin ein indischer Fürst ... ich bin ein weggelegtes Kind sowie Jesus Christus und Moses. Mein Vater ist Kaiser Franz Joseph.“ Am 25. VIII. (Traum?) „Daß ich ein Sohn vom Kaiserhause bin, daß ich mit Kaiser gegessen und gespeist habe." „Das träumt mir immer, da $ß$ ich der Kronprinz Rudolf bin . . . ich weiß aber nicht, ob es so ist ... . ich bin aber ein Jude.“ Am 13. VIII. hatte er bereits erzählt: „Ich bin ein Jude, ich bin der letzte Jude hier auf der Erde ..." Er ist der Isidor Eckstein, der Sohn von Oskar Meyer ... der war bucklig ... er hatte eine Adlernase aus dem Hause Habsburg. Am gleichen Tage hatte er aber auch geäußert, er sei der Sohn Kaiser Franz Josephs, heiße van der Bergen u. dgl. m. Wenn auch diese Äußerungen alle spielerisch gegeben werden, so ist die fortwährende Wiederholung doch psychologisch bedeutsam. Ob der Pat. wirklich geträumt hat, er sei Kronprinz Rudolf, 
ist unsicher, ich möchte es allerdings annehmen. Sonst tritt ja noch eine Reihe von Größenideen hervor. Er sei Großindustrieller, sei reich, habe Glück bei Frauen, doch ist all das viel episodischer. Er verkennt Personen, sieht seinen (verstorbenen) Bruder in Mitpatienten u. dgl. m. Hochgradige Ideenflucht und Erregung.

Die Krankengeschichte ist aus äußeren Gründen sehr unvollständig geblieben, es wurde nicht ersichtlich, ob und welche Motive aus früherer Zeit für die Manie bestimmend sind. Hingegen bleibt bemerkenswert, daß der Komplex der vornehmen Abstammung in der Psychose so sehr dominiert. Obwohl alles wie spielerisch zum Ausdruck kommt, ist es doch wahrscheinlich, daß sich hier Tieferliegendes ankündigt.

Bei einem Ủberblick über das gesamte Material ergibt sich zunächst, daß Komplexe in das Zustandsbild in fast allen Fällen eingebaut sind. Hiebei wird unter „Komplex" nur eine Erlebnisreihe verstanden, welche für das Individuum von wesentlicher Bedeutung ist und welche auch in der Psychose nicht als nebensächliche Episode aufhuscht. Es kann als fraglich erscheinen, ob in den Fällen 11 und 12 Komplexe nachgewiesen wurden. Im Falle 11 ist nicht ersichtlich geworden, mit welchen Erlebnissen die blasse und milde Erotik der Psychose verknüpft ist. Im Falle 12 tritt zwar der Komplex der vornehmen Abstammung immer wieder in den verschiedensten spielerischen $\mathrm{Ab}$ wandlungen hervor, doch wird nicht ersichtlich, inwieweit hier tiefere seelische Regungen zum Ausdruck kommen. In allen übrigen Fällen sind jedoch bestimmte Erlebnisse in der Struktur der Psychose wesentlich. Im Falle 1 ist es ein mißglückter Vergewaltigungsversuch an der Patientin, der die Manie einleitet, das Erlebnis wird hysteriform ausgesponnen, Im Falle 3, 4, 5 spielt die Stellung zu der Familie eine wesentliche Rolle. Der Tod des Vaters ist hier tiefeinschneidendes, nicht verwundenes Erlebnis; Liebe zum andersgeschlechtlichen, Haß gegen den gleichgeschlechtlichen Elternteil sind wesentliche Bestandteile. Fall 6 enthält als Hauptinhalt Trauer und Selbstanklage wegen des Todes des Mannes. Im Falle 7 werden die Kränkungen eines ganzen Lebens immer wieder heraufgespült. Im Falle 8 ist die Manie (oder manische Phase der Schizophrenie) Erfüllung aller Wünsche. Die Patientin erhält Geliebten und Vater in einem und wird Mutter aller. Im Falle 9 ist die manische Phase Erfüllung erotischer Aspirationen, und gleichzeitig hiermit übt das Ich magische Gewalten aus und erleidet sie. Im Falle 10 ist eine aus religiösen Quellen geschöpfte Halluzination Befreiung von Schuldgefühlen, welche aus infantiler Sexualbetätigung stammen.

Ich möchte auch hier betonen, daß die ,Komplexe“ geteilten Fälle nicht identisch sind mit jenen flüchtigen, mit der labilen Grundstimmung in Zusammenhang stehenden Depressionen und.jenen 
bekannten, rasch verschwindenden Wahngedanken (wiewohl noch zu untersuchen wäre, ob diese nicht aus einem "Grundwahn“ erfließen).

Das Vorhandensein der Komplexe, sei es in Form eines Wahnes, sei es in Form einer zugrunde liegenden ,Depression" als solcher, ist ja bekannt. Hinweise darauf finden sich in fast allen umfangreichen Bearbeitungen des Themas [etwa Kraepelin ${ }^{1}$ ), Stransky ${ }^{2}$ ), Reh m${ }^{3}$ )], man hat aber wohl verkannt, $\mathrm{da} B$ es sich hier nicht um besondere Zutaten ${ }^{4}$ ) handelt, sondern daß es wesentliche Bestandteile des Krankheitsbildes sind. Die Differenz rührt aus einer Verschiedenheit der Untersuchungsmethoden. Die gewöhnliche klinische Untersuchungsmethode genügt nicht. Man muß sich einer Technik bedienen, welche der psychoanalytischen nahesteht oder psychoanalytisch ist. Das heißt also tägliche, eingehende Beschäftigung mit den Fällen und vor allem auch Heranziehung der Träume und Phantasien zur Untersuchung. Breite Verwendung des freien Einfalls. Es ist zu bedauern, daß die klinische Psychiatrie von diesen Hilfsmitteln so wenig Gebrauch macht.

Über dieses deskriptive Ergebnis hinaus ist die Frage aufzuwerfen, ob diese Komplexe für die Genese der Manie von Bedeutung sind. Bereichert durch die Ergebnisse der Untersuchung kehren wir also zu der Fragestellung der Einleitung zurück. Da man in einer so großen Anzahl von Fällen Problemstellungen der Manie voraneilen sieht, die entweder (Fall 1, 3, 4, 5, 6) in der Manie bestehen bleiben oder in der Manie eine Lösung erfahren (Fall 8, 9, 10), so wird man wohl annehmen müssen, daß hier ein Faktor für die Genese der Manie gegeben sei. Man muß sich vorstellen, daß jeder psychische Konflikt Abwehrkräfte in Bewegung setzt, welche drängen, das unangenehme Erleben zu bewältigen und aus der Bewältigung Lust zu ziehen. Diese Bewältigung hat aber auch zum Ziele, das Individuum nun zu neuen Aufgaben fähig zu machen, ihm Aktionsfreiheit zu geben. Lust und Aktion habe ich zusammengefaßt mit dem Ausdruck ,manisches Fluidum". Schon normalerweise wird also manisches Fluidum bereit gestellt gegen drückende Probleme. Diese könnten nun frei werden durch das Verschwinden des Problems, etwa der Arme wird reich, der Trauernde erhält Nachricht, daß der Totgeglaubte lebt, die ersehnte Vereinigung mit dem Vater gelingt (Paula Skr.). Oder aber das Problem

1) 1. $\mathrm{c}$.

2) Das manisch-depressive Irresein. Leipzig, Wien 1911.

3) Das manisch-melancholische Irresein. Springer 1919.

4) Die paranoiden Zustandsbilder im manisch-depressiven Irresein sind wiederholt beschrieben worden. Zuletzt Schröder, Ungewöhnliche periodische Psychosen. Monatssehr. f. Neur. u. Psych. 44, H. 5, 1918. 'Die Spielbreite der Symptome beim manisch-depressiven Irresein und bei Degenerationspsychosen. Beihefte von Monatsschr. 1920, H. 8. Ewald, Paranoia und manisch-depressives Irresein. Diese Zeitschr. 49, 1919. 
wirke ständig als „Reizquelle für die Fluidumproduktion, so daß diese schließlich aus dem Reservoir überströmt und das Problem überflutet"“ (Fall 3, 4, 5, 6), oder aber das Problem wirke sich wahnhaft aus, und die Wahnerfüllung eröffnet die Reservoire, sei es, daß die Wahnerfüllung in der Manie erhalten bleibt (Fall 8, 9, 10) oder nicht. Man sieht also, daß der Zustand des Reservoirs von sehr wesentlicher Bedeutung sein muß. Man kann sich ja denken, daß alle vorausgegangenen Erlebnisse den Zustand dieses Reservoirs beeinflussen, doch ist das biologische Moment wohl das Entscheidende. Selbst in dem weitgehend aufgehellten Fall 10 kann man auf die Annahme nicht verzichten, daß dieses wesentlich sei. Dieses ist - dafür sprechen ja die bekannten Tatsachen - in der Mehrzahl der Fälle wohl als konstitutionell aufzufassen. Die psychologischen Verhältnisse werden jedoch nicht geändert, wenn man annimmt, es seien erworbene Abänderungen des Körpers maßgebend. Macht man sich aber klar, daß „der Zustand des Energiereservoirs" für die Form jedes „Freudenausdrucks" bestimmend ist, daß aber trotzdem durch vorgegangene Erlebnisse ein solcher grundlegend verändert sein kann (im Sinne der Steigerung oder $\mathrm{Ab}$ schwächung), so wird man wenigstens theoretisch die Möglichkeit akzeptieren müssen, daß bei einem biologisch normalen Reservoir durch Erlebnisse eine Manie ausgelöst werden könnte. Denn auch das Reservoir dürfte als körperliche Funktion psychisch ansprechbar sein.

Damit fügt sich aber die Manie vollkommen jenen allgemeinen Anschauungen über das Wechselspiel ,psychischer" und ,somatischer" Kausalität ein, über das ich an anderer Stelle berichtet habe ${ }^{1}$ ). Dort führte ich aus, daß jedes psychische Erlebnis eine Auswirkung habe, daß aber die Art dieser Auswirkung bedingt sei durch somatische Faktoren, diese somatischen Faktoren änderten das "Niveau“ der Auswirkung. Niveauänderungen können aber auch durch psychische Einwirkung hervorgerufen werden. Ein psychisches Erlebnis kann sich nach diesen Ausführungen doppelt auswirken, einmal in psychische Erlebnisse, welche in der Richtung der durch sie geweckten Tendenzen liegen, also etwa in eine Phantasie, aber auch in ,,eine Niveauänderung“", welche dann die Phantasie zur Halluzination machen könnte. Der Begriff „Änderung im manischen Reservoir" fügt sich also dem allgemeinen Begriffe der „Niveauänderung“ ein. Die Kombination Wahnbildung + manische Erregung, die ja wiederholt mitgeteilt wurde, zeigt, daß die Niveauänderung in eine Anzahl von Einzeländerungen auflösbar ist. Hier ist einersteils der „Realitätswert" eines Gedankens verändert, der Gedanke zum Wahne umgearbeitet, andernteils ist aber auch „im manischen Reservoir" etwas vorgegangen.

1) Über die kausale Bedeutung psychoanalytisch gewonnenen Materiales. Wiener klin. Wochenschr. 1921. 
Man kann sagen, daß im Falle 2 sicherlich sowohl für die depressive Verwirrtheit als auch für die nachfolgende manische Phase die somatische Erkrankung und nicht das vorausgegangene psychische Erleben bestimmend war. Es ist vom Psychischen aus gesehen eine ,autonome" Schwankung im Reservoir. Trotzdem drängen sich offenbar tiefverankerte Wünsche: Heirat mit der Schwester, Beseitigung des Vaters in die Umschlagszeit zwischen depressiver Verwirrtheit und Manie. Man muß annehmen, daß jedes psychische Erleben, jeder versteckte Wunsch die Tendenz hat, sich auszuwirken und daß je nach dem $\mathrm{Zu}$ stand des Niveaus diese Tendenz sich durchsetzen kann oder nicht. Die autonome Schwankung im Niveau schafft solche Möglichkeiten. Es ist nun sehr beachtenswert, daß die Schwankung im ,,affektiven Reservoir" (bezüglich des ,depressiven Fluidums" lassen sich sehr ähnliche Aufstellungen machen wie bezüglich der manischen), obwohl biologisch begründet, einen ähnlichen Rhythmus zeigt, wie ein psychischer Ablauf. Es liegt nahe, den normalen Affektablauf auf ähnliche biologische Mechanismen zu beziehen, doch wage ich nicht, den Gedanken auszudenken, daß der psychische Ablauf das Urbild biologischer Rhythmik sei.

Der Begriff des manischen Fluidums bedarf noch einer Erörterung. Er wurde bisher verwendet zur Darstellung eines psychischen Ablaufes, zur besseren Erfassung kausaler Zusammenhänge. Aber ich muß betonen, offenbar erlebt ja das Individuum auch, daß ein Erlebnis das „Reservoir" aufruft und es erlebt ja auch, daß jetzt ,,manisches Fluidum" vorflutet. Ganz allgemein: Das Individuum erlebt die Niveauänderung direkt, insofern als es Änderung in der Auswirkung von Tendenzen erlebt. Ein Mensch, der das eine Mal bei einem "freudigen Ereignis“" ruhig bleibt und das andere Mal in einen Freudenschrei ausbricht und zu tanzen beginnt, erlebt wohl schon anders, noch bevor er den ersten Laut und die erste Bewegung von sich gab. Die hier dargestellten Kausalzusammenhänge sind demnach auch Erlebniszusammenhänge.

Zur Erklärung des Gesamtbildes müssen also sowohl die vorausgegangenen Erlebnisse als auch die „Konstitution“ herangezogen werden. Abraham, der sich vom psychoanalytischen Standpunkt um das manisch-depressive Irresein bemüht hat, hat den Faktor der Konstitution vernachlässigt. Wollte man die Änderung im „Reservoir“" nur von den Erlebnissen herleiten, so müßte zumindest die Sonderart dieser Erlebnisse aufgezeigt werden, wobei noch immer die Frage aufzuwerfen wäre, ob nicht schon die Sonderart der Erlebnisse durch die Konstitution mitbestimmt sei. Außerdem ist es weder Abraha m noch mir gelungen, solche „typische" Erlebnisse nachzuweisen.

Wichtig ist auch eine andere Fragestellung, die Abraha m aufwirft. 
Er betont, daß der Manische Neigung habe zu Witzen und daß er einen Teil seiner „Lust“ aus dieser Witzeslust beziehe ${ }^{1}$ ). Der Witz hat ja Hemmungen zu überwinden, bevor er zu seinem Ziel kommt. Warum hat der Manische Hemmungen, woher nimmt er sie? Ist vielleicht der fortwährend auftauchende Komplex auch ein solcher ständiger Reiz der Úberwindung? Das Hervorstechende im Bilde der Manie ist ja der Hunger nach neuen Eindrücken. Die manische Lust muß also eine rasch abklingende sein, denn Lust, die andauert, kann ja nicht zu den fortwährenden neuen Anstrengungen führen, die den Maniacus auszeichnen. Wenn man also das ,,manische Fluidum“ näher beschreiben wollte, müßte dieses Moment sehr berücksichtigt werden. Es liegt nahe, zwischen der Ideenflucht, welche auf einer nicht genügend nachhaltigen Wirksamkeit der Obervorstellungen (Lie p man n) beruht, und dem raschen Verblassen der Lust engere Beziehungen anzunehmen ... Ich habe den Typus lustvollen Erlebens, den wir als Seligkeit benennen, in der Einleitung dem Erleben der Manie gegenübergestellt, doch gibt es zweifellos Übergänge [so z. B. Fall 10 und $11^{2}$ )]. Die Mannigfaltigkeit der Gefühlsnuancen, welche wir im Rahmen dieser Erkrankung antreffen, kann nicht Gegenstand dieser Abhandlung sein. Eine künftige derartige Untersuchung hätte sich auch mit der Frage auseinanderzusetzen, was denn mit den Gefühlen geschieht, welche den aktuellen depressiven Erlebnissen der Manie angehören. Es ist hier noch eine Fülle von Fragen der deskriptiven und dynamischen Psychologie der Gefühle zu erledigen.

Diese Untersuchungen gehen darauf aus, an die Stelle einer Psychologie ruhender Gebilde eine Psychologie seelischer Entwicklungen zu setzen. Es genügt nicht, irgendwelche statisch gedachten Funktionen, die zu einem seelenlosen Mosaik angeordnet sind, als gehemmt oder erregt zu denken. Sondern man muß versuchen, den Verlauf und die zeitliche Entwicklung der seelischen Vorgänge zu studieren. Auch in der Manie müssen zwischen dem Erleben der gesunden Tage und dem der Psychose Brücken existieren. Es gibt keine Erkrankung, welche imstande wäre, seelische Abläufe mechanisch zu zertrennen. Dieser seelische Ablauf ist aber ein kausaler. Die verständlichen Zusammenhänge sind auch kausale Zusammenhänge, es kommt nun noch etwas

1) Abraham sieht hierin einen infantilen Zug. Hier kann ich ihm nicht folgen. Die Ähnlichkeit im Verhalten Manischer mit dem von Kindern beschränkt sich auf den Bewegungsreichtum, die Lust an Bewegungen und die allgemeine Heiterkeit; den Begriff der Regression hier zu verwerten, halte ich nicht für nutzbringend.

2) Die expansive Autopsychose, die Boström (diese Zeitschr. 60, 213. 1920) beschreibt, hat sicherlich zur Manie die engste Verwandtschaft, und es ist wohl nur eine Geschmackseache, ob man sie von dieser sondert oder nicht. Die klinischen Gruppierungen haben überhaupt etwas sehr Unbefriedigendes. 
hinzu, nämlich das Erlebnis des Zusammenhangs. Jenes unerklärliche Verbunden- und Ineinanderverschränktsein. Das ist aber ein Plus, das zur kausalen Verbundenheit hinzutritt ${ }^{1}$ ). Es ist eine Eigentümlichkeit der kausalen-psychischen Reihe, daß sie, solange nur das Leben besteht, ihre Kontinuität bewahrt. Somatische Einbrüche erzeugen nur „Niveauänderungen“. Es muß also gefordert werden, daß die Verständlichkeit eines Erlebens da ist, auch wenn ein psychischer Prozeß eingegriffen hat. Versuche aus der Verständlichkeit oder Nichtverständlichkeit eines Zusammenhanges zu schließen, ob eine organische Erkrankung bestehe oder nicht, müssen daher prinzipiell als verfehlt betrachtet werden.

Ich verkenne die Schwierigkeiten nicht, die sich Versuchen dynamischer Darstellungen entgegenstellen. Es bedürfte bereits eingehender Erörterungen, um klar festzulegen, welche Beziehungen zwischen dem, was hier ,,manisches Fluidum" und Niveauveränderung genannt wurde, und den Energieumsetzungen bestehen, welche Breuer und Freudi2) sowie Freud so eingehend beschrieben haben. Freud hat ja immer wieder auf die Wichtigkeit dieser Energieumwandlungen hingewiesen. Hier nur der Hinweis, daß es sich bei ,manischem Fluidum" um einen Hilfsbegriff handelt, welcher auf einen außerpsychischen Faktor zielt, der die Dynamik der Abläufe regelt. Außerpsychische in dem gleichen Sinne wie die Einwirkung des Alkohols ist, die zum Rausche führt. Auch dort ist die "Niveauänderung“ außerpsychisch bedingt. Allerdings ändert dieses Außerpsychische den Ablauf der Akte, nicht nur ihre Dynamik, sondern auch das Erlebnis selbst. Es wird also im Grunde mit dem Ausdrucke Niveauveränderung ",manisches Fluidum“ ein Faktor gekennzeichnet, der ,,somatisch“ die „Energieproduktion“ regelt. Ein solcher, die Energieproduktion regulierender Faktor muß aber in jedem seelischen Ablauf enthalten sein.

Man könnte nun versuchen, eben diesen Faktor als ,das Unbewußte" ${ }^{\text {"3) }}$ zu bezeichnen. Dieser Faktor ist aber nicht psychisch, er war nie psychisch, und er kann es nicht werden. Es hat also gar keinen Sinn, hier von unbewußt Psychischem zu sprechen. Man kann allerdings sagen, dieser Faktor spiegelt sich in der Art der Akte (Noesen) und in ihrer dynamischen Wirkung. Ich möchte allerdings den Standpunkt vertreten, daß die dynamische Wirkung der Noese in der Art

1) Um die Darstellung dieses Zusammenhanges haben sich Jas pers (Lehrbuch der Psychopathologie, II. Aufl. 1920) und Lewin (Das Hysterieproblem, Monatsschrift f. Neurol. u. Psych. 48, 204. 1920) verdient gemacht. Sie haben jedoch dessen kausale Bedeutung verkannt. Kronfeld (Das Wesen der psychiatrischen Erkenntnis, Springer 1920) und Kretsch mer (diese Zeitschr. 57, 1920) haben hier richtiger gesehen.

2) Studien über Hysterie. 1895.

3) Vgl. hierüber z. B! meine Arbeit „Über Identifizierung“. Diese Zeitschr. 59. 
der Noese erlebt wird. Mit anderen Worten, die Stoßkraft des Impulses, die Impulsenergie wird erlebt und ist gleichzeitig auch als dynamischer Faktor zu werten. Die Niveauänderung wird nicht erlebt, ist außerpsychisch, spiegelt sich aber in dem Erleben.

Gewiß ist es einfacher, Seelisches nur als ruhend zu betrachten, sich mit deskriptiver Psychologie zu begnügen. Wer aber das eigentliche Wesen des Seelischen in einem Strömen in der Zeit sieht, wird vordringen müssen zu einem nachfühlenden Verstehen, und wird eine Ordnung der Mannigfaltigkeit nach kausalen Prinzipien anstreben müssen. Denn, um es nochmals zu sagen: Seelische Geschehnisse stehen zueinander in kausalen Beziehungen. Das Seelische reicht über das Kausale hinaus, aber es schließt es in sich, und wir dürfen vermuten, daß die physische Kausalität nur ein Einlegen der psychischen Kausalität in die Dinge ist. 